NBER WORKING PAPER SERIES

\title{
DO FEMALE EXECUTIVES MAKE A DIFFERENCE? THE IMPACT OF FEMALE LEADERSHIP ON GENDER GAPS AND FIRM PERFORMANCE
}

\author{
Luca Flabbi \\ Mario Macis \\ Andrea Moro \\ Fabiano Schivardi \\ Working Paper 22877 \\ http://www.nber.org/papers/w22877 \\ NATIONAL BUREAU OF ECONOMIC RESEARCH \\ 1050 Massachusetts Avenue \\ Cambridge, MA 02138 \\ December 2016
}

We thank Manuel Bagues, John Earle, Stephan Eblich, Nicola Lacetera, Giovanni Pica, Kathryn Shaw, and seminar participants at several conferences and institutions for very useful comments and suggestions. Partial funding from the IDB Economic and Sector Work grant RG-K1321, the PRIN grant 2010XFJCLB_001 and the RAS L.7 project CUP:F71J11001260002 is gratefully acknowledged. The views expressed herein are those of the authors and do not necessarily reflect the views of the National Bureau of Economic Research.

NBER working papers are circulated for discussion and comment purposes. They have not been peer-reviewed or been subject to the review by the NBER Board of Directors that accompanies official NBER publications.

(C) 2016 by Luca Flabbi, Mario Macis, Andrea Moro, and Fabiano Schivardi. All rights reserved. Short sections of text, not to exceed two paragraphs, may be quoted without explicit permission provided that full credit, including $(\odot$ notice, is given to the source. 
Do Female Executives Make a Difference? The Impact of Female Leadership on Gender Gaps and Firm Performance Luca Flabbi, Mario Macis, Andrea Moro, and Fabiano Schivardi

NBER Working Paper No. 22877

December 2016

JEL No. J7,M12,M5

\section{ABSTRACT}

We investigate the effects of female executives on gender-specific wage distributions and firm performance. We find that female leadership has a positive impact at the top of the female wage distribution and a negative impact at the bottom. Moreover, the impact of female leadership on firm performance increases with the share of female workers. Our empirical strategy accounts for the endogeneity induced by the non-random assignment of executives to firms by including in the regressions firm fixed effects, by generating controls from a two-way fixed effects regression, and by building instruments based on regional trends. The empirical findings are consistent with a model of statistical discrimination where female executives are better equipped at interpreting signals of productivity from female workers. The evidence suggests substantial costs of underrepresentation of women at the top of the corporate hierarchy

\author{
Luca Flabbi \\ University of North Carolina - Chapel Hill \\ 107 Gardner Hall, CB 3305 \\ Chapel Hill, NC 27599-3305 \\ luca.flabbi@gmail.com \\ Mario Macis \\ Johns Hopkins University \\ Carey Business School \\ 100 International Drive, Office 1333 \\ Baltimore, MD 21202 \\ and IZA \\ and also NBER \\ mmacis@jhu.edu
}

\author{
Andrea Moro \\ Department of Economics \\ Vanderbilt University \\ VU Station B \#351819 \\ Nashville, TN 37235 \\ andrea.moro@vanderbilt.edu \\ Fabiano Schivardi \\ Bocconi University \\ Via Roentgen 1 \\ Milan, 20136 \\ Italy \\ Italy \\ and EIEF \\ fabiano.schivardi@gmail.com
}

A Web Appendix is available at

https://www.dropbox.com/s/9cr2kyx52tzvdee/femaleceo-webappendix.pdf?dl=0 


\title{
Do Female Executives Make a Difference? The Impact of Female Leadership on Gender Gaps and Firm Performance*
}

\author{
Luca Flabbi, Mario Macis, Andrea Moro, and Fabiano Schivardi
}

November 30, 2016

\begin{abstract}
We investigate the effects of female executives on gender-specific wage distributions and firm performance. We find that female leadership has a positive impact at the top of the female wage distribution and a negative impact at the bottom. Moreover, the impact of female leadership on firm performance increases with the share of female workers. Our empirical strategy accounts for the endogeneity induced by the non-random assignment of executives to firms by including in the regressions firm fixed effects, by generating controls from a two-way fixed effects regression, and by building instruments based on regional trends. The empirical findings are consistent with a model of statistical discrimination where female executives are better equipped at interpreting signals of productivity from female workers. The evidence suggests substantial costs of under-representation of women at the top of the corporate hierarchy.
\end{abstract}

JEL Codes: M5, M12, J7, J16.

Keywords: executives' gender, gender gap, firm performance, glass ceiling, statistical discrimination

*Flabbi: University of North Carolina-Chapel Hill, CPC-UNC, CHILD-CA and IZA, luca.flabbi@unc.ed. Macis: Johns Hopkins University, IZA and NBER, mmacis@jhu.edu. Moro: Vanderbilt University, andrea@andreamoro.net. Schivardi: Bocconi University, IGIER, EIEF and CEPR, fabiano.schivardi@unibocconi.it. We thank Manuel Bagues, John Earle, Stephan Eblich, Nicola Lacetera, Giovanni Pica, Kathryn Shaw, and seminar participants at many conferences and institutions for very useful comments and suggestions. Partial funding from the IDB Economic and Sector Work grant RG-K1321, the PRIN grant 2010XFJCLB_001 and the RAS L.7 project CUP: F71J11001260002 is gratefully acknowledged. 


\section{Introduction}

This paper investigates how female executives affect firm-level workers' wage distributions and performance using a unique matched employer-employee panel dataset representative of the Italian manufacturing sector.

A growing literature shows that executives' characteristics such as management practices, style, and attitudes towards risk can have an effect on firm outcomes. ${ }^{1}$ We focus on one of these executives' characteristics: gender. Our focus on gender follows from the abundant evidence of systematic gender differentials in the labor market. ${ }^{2}$ With respect to executives, research has highlighted that women are almost ten times less represented than men in top positions in firms. ${ }^{3}$ For example, recent U.S. data show that even though women are a little more than $50 \%$ of white collar workers, they represent only $4.6 \%$ of executives. ${ }^{4}$ Our own Italian data show that about $26 \%$ of workers in the manufacturing sector are women compared with only $3 \%$ of executives and $2 \%$ of CEOs. Together, these facts suggest that it is important to study the realtion between somen's under-representation among top executives and firms' outcomes.

This paper provides four contributions to the existing literature. First, we develop a theoretical framework highlighting a potential channel of interaction between female executives, female workers, wage policies, job assignment, and overall firm performance. The model implies efficiency costs of women's under-representation in leadership positions, and generates original empirical predictions. Second, we investigate the relationship between female leadership and the gender-specific wage distributions at the firm level. Unlike most of the previous literature, our theoretical

\footnotetext{
${ }^{1}$ Bloom and Van Reenen (2007) is one of the first contributions emphasizing differences in management practices. See also a recent survey in Bloom and Van Reenen (2010). A growing literature showing the effects of CEO characteristics follows the influential paper of Bertrand and Schoar (2003). Among recent contributions, see Bennedsen et al. (2012), Kaplan et al. (2012), or Lazear et al. (2012). For research on executives' overconfidence, see Malmendier and Tate (2005). For theoretical contributions, see for example Gabaix and Landier (2008) and Tervio (2008). For contributions focusing on both executive and firm characteristics, see Bandiera et al. (2011) and Lippi and Schivardi (2014).

${ }^{2}$ For an overview of the gender gap in the U.S. labor market in the last twenty years, see Blau and Kahn (2004), Eckstein and Nagypal (2004) and Flabbi (2010).

${ }^{3}$ Evidence from U.S. firms is based on the Standard and Poor's ExecuComp dataset, which contains information on top executives in the S\&P 500, S\&P MidCap 400, and S\&P SmallCap 600. See for example, Bertrand and Hallock (2001), Wolfers (2006), Gayle et al. (2012), Dezsö and Ross (2012). The literature on other countries is quite thin: see Cardoso and Winter-Ebmer (2010) (Portugal), Ahern and Dittmar (2012) and Matsa and Miller (2013) (Norway), Smith et al. (2006) (Denmark), Gagliarducci and Paserman (2015) (Germany), and Flabbi et al. (2016a) (Latin America). A related literature is concerned with under-representation of women at the top of the wage distribution, see for example Albrecht et al. (2003). Both phenomena are often referred to as a glass-ceiling preventing women from reaching top positions in the labor market.

${ }^{4}$ Our elaboration on 2012 Current Population Survey and ExecuComp data.
} 
framework leads us to focus not on the effects at the mean but on the differential impacts over different points of the wage distribution. Third, we investigate the relationship between female leadership and firm performance, focusing on the interaction between female leadership and gender composition of the workforce. We concentrate on indicators of firm performance that are less volatile and closer to firm productivity than those used by previous literature. Previous contributions have typically used measures of financial performance while we build measures of sales per worker, value added per worker and Total Factor Productivity (TFP). Finally, we perform a series of partial-equilibrium counterfactual exercises to compute the cost of women's under-representation in top positions in organizations.

In Section 2 we present our theoretical framework and derive its empirical implications. Our model extends the seminal statistical discrimination model of Phelps (1972) to include two types of jobs, one characterized by complex tasks and the other by simple tasks, and two types of CEOs, male and female. Based on a noisy ability signal, CEOs assign workers to jobs and wages. We assume that CEOs are better (more accurate) at reading signals from workers of their own gender. ${ }^{5}$ We also assume that complex tasks require more skills to be completed successfully so that it is optimal to assign more skilled workers to complex tasks. After defining the equilibrium generated by this environment, we focus on the empirical implications of a female CEO taking charge of a male CEO-run firm. Thanks to the more precise signal they receive from female workers, female CEOs reverse the statistical discrimination suffered by women, adjusting their wages and reducing the mismatch between female workers' productivity and job requirements. The model delivers two sharp empirical implications:

1. Female workers at the top of the wage distribution receive higher wages when employed by a female CEO than when employed by a male CEO. Female workers at the bottom of the wage distribution receive lower wages when employed by a female CEO. The impact of female CEOs on the male workers' distribution has the opposite signs: negative at the top and positive at the bottom of the distribution.

2. The performance of a firm led by a female CEO increases with the share of female workers.

These results follow from the assumption that female CEOs are better at processing information about female workers' productivity. Therefore, wages of females employed by female CEOs are more sensitive to individual productivity, delivering the

\footnotetext{
${ }^{5}$ We discuss this assumption in Subsection 2.3.
} 
first implication. Moreover, female CEOs improve the allocation of female workers across tasks, delivering the second implication.

Our data, described in detail in Section 3, include all workers employed by firms with at least 50 employees in a representative longitudinal matched employeremployee sample of Italian manufacturing firms observed between 1982 and $1997 .{ }^{6}$ Because we observe all workers and their compensation, we can evaluate the impact of female leadership on the wage distribution at the firm level. Moreover, we can obtain a precise measurement of the leadership at the firm and assess the proportion of women among its ranks. Because the data set is rich in firm-level characteristics, we can compute several measures of firm performance which are less volatile and more representative of firms productivity than previous literature. Finally, since we can merge this sample with social security data containing the complete labor market trajectories of all workers who ever transited through any of the firms in the sample, we can identify firm, worker and executive fixed effects that help in dealing with the endogeneity issues affecting the regressions of interest.

We describe our empirical strategy and present the estimation results in Section 4. We analyze the impact of female leadership on wages of male and female workers allowing for heterogenous effects across the distribution. We also study the impact of female leadership on firm performance allowing for interaction with the gender composition at the firm. Assessing the impact of female executives on any firm-level outcome faces a fundamental identification problem: executives are endogenously matched with firms. A typical strategy used by previous literature to reduce the bias has been to focus only on within-firm variation. We use the same firm fixed effects strategy but we add additional controls for both observed and unobserved heterogeneity of the executives and of the non-executive workforce at the firm. Unobserved heterogeneity controls are obtained from a first step two-way fixed effect wage regression that we can estimate thanks to the large number of complete labor market trajectories we observe in our data set. To address the potential endogeneity induced by unobservable time-varying firm characteristics, in the robustness section we also propose an instrumental variable (IV) strategy. The identifying assumption is that aggregate trends in the proportion of female executives at the regional level are exogenous with respect to the time-varying firm-level heterogeneity we are concerned about.

Our results show that the impact of female executives is positive on women at the top of the wage distribution but negative on women at the bottom of the wage

\footnotetext{
${ }^{6}$ This is the only period over which our data are available and this is the reason why we cannot provide an analysis using more recent data.
} 
distribution. We estimate the opposite effect on men. As a result, we find that female leadership at the firm reduces the gender wage gap at the top of the wage distribution and widens it at the bottom, with essentially no effects on average.

We estimate that the impact of female leadership on firm performance - as measured by sales per worker, value added per worker, and total factor productivity (TFP) - is a positive function of the proportion of female workers employed by the firm. The magnitude of the impact is substantial: a female CEO would increase overall sales per employee by about $3.7 \%$ if leading a firm employing a proportion of women equal to the average in the sample (about 20\%.) All results are robust to the use of our IV strategy and to an additional set of robustness exercises, dealing with the selection induced by entry and exit of firms and workers, the definition of female leadership, the specific empirical specification, and the measure of firm performance.

Using our estimates, we perform a partial equilibrium counterfactual exercise to compute the cost of women's under-representation in leadership positions. The effects of increasing the share of female-led firms critically depends on how female CEO are assigned to firms. If they are randomly scattered across firms, productivity increases by little or, in some cases, it even decreases. If instead, female CEOs are assigned to all firms with at least a $20 \%$ proportion of female workers (about 50 percent of the sample), sales per worker would increase by $14 \%$ in the "treated" firms, and by $6.7 \%$ in the overall sample of firms.

Even though our theoretical framework provides a unified explanation for the full set of estimation results we obtain, we discuss in Section 5 other relevant theories of gender inequality that can plausibly explain at least some of them. We consider explanations using taste-based discrimination models and explanations based on complementarities in technology affecting productivity by gender. Among the second set of explanations, we find that mentoring (Athey et al. (2000)) is consistent with all of our most precisely estimated results and is at odds with only a subset of our least precisely estimated results. We conclude that, although the evidence lines up more precisely with the mechanism we propose, additional work is needed to disentangle the source of gender-specific complementarities at the firm.

There is a large literature studying gender differentials in the labor market, and a fairly developed literature studying gender differentials using matched employeremployee data. However, the literature on the relationship between the gender of the firm's executives and gender-specific wages is scant and has focused on the effect on average wages, not on the effect over the entire wage distribution. Bell (2005) and Albanesi et al. (2015) study the impact of female leadership in US firms but only on executives' wages. Cardoso and Winter-Ebmer (2010) consider the effect on 
all workers in a sample of Portuguese firms but without allowing for heterogeneous effects over the wage distribution. Fadlon (2015) tests a model of statistical discrimination similar to ours and assesses the impact of supervisors' gender on workers' wages using U.S. data but does not focus on the wage distribution and does not look at wages at the firm level. Gagliarducci and Paserman (2015) use German linked employer-employee data to study the effect of female leadership at the firm on establishments and workers outcomes. They find no significant association between outcomes and female leadership, including full-time and part-time log wages for men and women, once firm fixed-effects are introduced. Lucifora and Vigani (2016) study the impact of the gender of the immediate supervisor on various workers outcomes for a large set of European countries. They focus on self-reported discrimination and they estimate that female supervisors reduce the gender gap. However, their data do not allow for a firm fixed effects approach and the results are from cross-sectional data with some controls for selection. A related literature, sparked by recent reforms in European countries, looks at the impact of the gender of a firm's board members instead of its executives. Bertrand et al. (2014) documents that a reform mandating gender quotas for the boards of Norwegian companies reduced the gender gap in earnings within board members but did not have a significant impact on overall gender wage gaps.

Existing literature on the effect of female leadership on firm performance is also limited. Most of the contributions focus on stock prices, stock returns and market values as measures of firms performance ${ }^{7}$ and on the proportion of women among board members as measure of female leadership. ${ }^{8}$ Instead, we propose measures of firm performance that are less volatile and closer to actual firm productivity (sales per worker, value added per worker and TFP) and measures of female leadership relating more directly to the day-to-day running of the firm (female CEO and female proportion of women among top executives). ${ }^{9}$

\footnotetext{
${ }^{7}$ See for example, Wolfers (2006), Albanesi and Olivetti (2009), Ahern and Dittmar (2012); in the strategy literature, Dezsö and Ross (2012), Adams and Ferreira (2009), Farrell and Hersch (2005).

${ }^{8}$ See for example, Matsa and Miller (2013), which looks at operating profits, and Rose (2007), which looks at Tobin's Q.

${ }^{9}$ Among the few contributions looking at the impact of female executives on non-volatile measures of firm performance are Smith et al. (2006), with information on value added and profits from a panel of Danish firms and Gagliarducci and Paserman (2015), with information on business volume and investment from a sample of German linked employer-employee data.
} 


\section{Theoretical Framework}

We present a simple signal extraction model where inequalities are generated by employers' incomplete information about workers' productivity and where employers' gender matters. The main assumption of our model is that female and male executives are better equipped at assessing the skills of employees of their same gender. As discussed in greater detail below, this may be the result of better communication and better aptitude at interpersonal relationships among individuals of the same gender, of more similar cultural background shared by individuals of the same gender, or other factors. From the model we derive a set of implications that we test in our empirical analysis.

\subsection{Environment}

We extend the standard statistical discrimination model in Phelps (1972) to include two types of employers (female and male), and two types of jobs (simple and complex). The two-jobs extension allows us to obtain implications for efficiency (productivity), which is one focus of our empirical analysis. ${ }^{10}$ Female $(f)$ and male $(m)$ workers have ability $q$ which is distributed normally with mean $\mu$ and variance $\sigma^{2}$. Ability, productivity and wages are expressed in logarithms. CEOs observe a signal of ability $s=q+\epsilon$, where $\epsilon$ is distributed normally with mean 0 and variance $\sigma_{\epsilon g}^{2}$ where $g$ is workers' gender $m$ or $f$. The signal's variance can be interpreted as a measure of the signal's information quality. Employers assign workers to one of two jobs: one requiring complex $(c)$ tasks to be performed and the other requiring simple tasks $(e)$ to be performed. To capture the importance of correctly assigning workers to tasks, we assume that mismatches are costlier in the complex job, where workers with higher ability are more productive. One way to model this requirement is by assuming that the dollar value of workers' productivity in the complex (simple) job is $h(l)$ if workers have ability $q>\bar{q}$, and $-h(-l)$ otherwise, with $h>l \geq 0 .{ }^{11}$

Firms compete for workers and maximize output given wages. Workers care only about wages and not about job assignment per se.

\footnotetext{
${ }^{10}$ In the standard model of Phelps (1972) discrimination has a purely redistributive nature. If employers were not allowed to use race as a source of information, production would not increase, but this is due to the extreme simplicity of the model. See Fang and Moro (2011) for details.

${ }^{11}$ The threshold rule for productivity is a strong assumption, which we adopted to simplify the derivation of the model's outcome, but it is not crucial. What is crucial is that productivity increases with ability, and that lower ability workers are more costly mismatched in the complex job.
} 


\subsection{Homogenous CEOs}

It is helpful to start the analysis by exploring the effect of the worker's signal precision on labor market outcomes when all CEOs are of the same gender, let us assume male; in subsection 2.3 we will extend the environment to include female CEOs.

Firms' competition for workers implies that in equilibrium each worker is paid his or her expected marginal product, which depends on her expected ability $E(q \mid s)$. Standard properties of the bivariate normal distribution ${ }^{12}$ imply that $E(q \mid s)=(1-$ $\left.\alpha_{g}\right) \mu+\alpha_{g} s$, where $\alpha_{g}=\sigma^{2} /\left(\sigma_{\epsilon g}^{2}+\sigma^{2}\right)$. Expected ability is a weighted average of the population average skill and the signal, with weights equal to the relative variance of the two variables. When the signal is perfectly informative $\left(\sigma_{\epsilon g}=0\right)$, the population mean is ignored; when the signal is pure noise $\left(\sigma_{\epsilon g}=\infty\right)$, expected ability is equal to the population average. With a partially informative signal, the conditional expected ability is increasing in both $q$ and $s$.

The conditional distribution, which we denote with $\phi_{g}(q \mid s)$ is also normal, with mean equal to $E(q \mid s)$ and variance $\sigma^{2}\left(1-\alpha_{g}\right), g=\{m, f\}$. Denote the corresponding cumulative distributions with $\Phi_{g}(q \mid s)$.

It is optimal for employers to use a cutoff job assignment rule: workers will be employed in job $c$ if $s \geq \bar{s}_{g}$. The cutoff $\bar{s}_{g}$ is computed by equating expected productivity in the two jobs, as the unique solution to

$$
h(\operatorname{Pr}(q \geq \bar{q} \mid s, g)-\operatorname{Pr}(q<\bar{q} \mid s, g))=l(\operatorname{Pr}(q \geq \bar{q} \mid s, g)-\operatorname{Pr}(q<\bar{q} \mid s, g)) .
$$

We denote this solution with $\bar{s}\left(\sigma_{\epsilon g}\right)$ to stress its dependence on the signal's precision. The worker with signal $\bar{s}\left(\sigma_{\epsilon g}\right)$ has the same expected productivity (zero) in both jobs. ${ }^{13}$ Competition ensures that wages $w$ are equal to expected marginal products, which are functions of the signal received and the worker's gender:

$$
w\left(s ; \sigma_{\epsilon g}\right)=\left\{\begin{array}{ll}
l\left(1-2 \Phi_{g}(\bar{q} \mid s)\right) & \text { if } s<\bar{s}_{g} \\
h\left(1-2 \Phi_{g}(\bar{q} \mid s)\right) & \text { if } s \geq \bar{s}_{g}
\end{array} .\right.
$$

We now explore the properties of the wage schedule as a function of the signal's noise variance $\sigma_{\epsilon g}^{2}$. Figure 1 displays the outcome for workers with two different

\footnotetext{
${ }^{12}$ See Eaton (1983)

${ }^{13}$ Equation 2.1 is satisfied when $\operatorname{Pr}(q \geq \bar{q} \mid s, g)=1 / 2$ because of the extreme symmetry of the setup. This implies also that expected productivity is zero for workers with signal equal to the threshold. This can be relaxed: all that is needed to obtain our qualitative implications is that productivity increases with ability, and a comparative advantage to place higher ability workers in the complex job.
} 


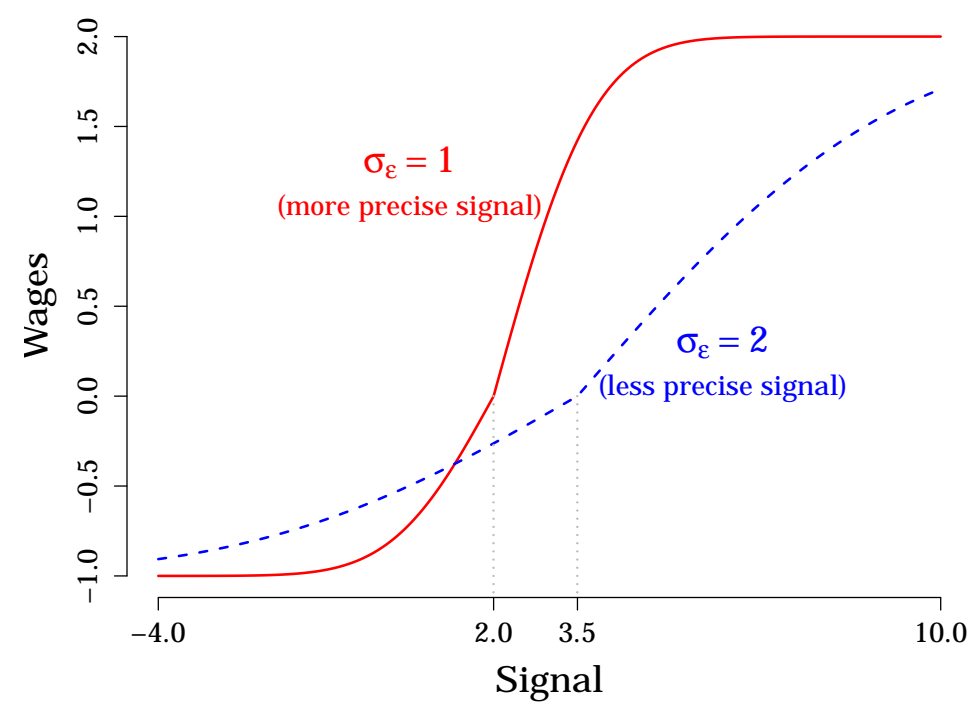

Figure 1: Simulation of the solution to the problem with parameters $\sigma=1$, $\bar{q}=1.5, \mu=1, h=2, l=1$.

values of $\sigma_{\epsilon g}^{2}$. The red continuous line displays the equilibrium wages resulting from a more precise signal than the blue dashed line. As standard in statistical discrimination models, the line corresponding to the more precise signal is steeper than the line corresponding to the less precise signal. This is the direct implication of putting more weight on the signal in the first case than in the second. As a result of one of our extensions - the presence of job assignment between simple and complex jobs - the two lines also display a non-standard feature: a kink in correspondence to the threshold signal. The kink is a result of the optimal assignment rule: workers with signals below the threshold are assigned to the simple job, where ability affects productivity less than in the complex job, therefore both wage curves are flatter to the left of the thresholds than to the right of the thresholds.

The following proposition states that the expected marginal product of a worker is higher when the signal is noisier if the signal is small enough. Conversely, for a high enough signal, the expected marginal product will be lower the noisier the signal. Formally,

Proposition 1. Let $w\left(s ; \sigma_{\epsilon g}\right)$ be the equilibrium wage as a function of the workers' signal for group $g$, extracting a signal with noise standard deviation equal to $\sigma_{\epsilon g}$. If $\sigma_{\epsilon f}>\sigma_{\epsilon m}$ then there exists $\widehat{s}$ such that $w\left(s ; \sigma_{\epsilon f}\right)>w\left(s ; \sigma_{\epsilon m}\right)$ for all $s<\widehat{s}$ and $w\left(s ; \sigma_{\epsilon f}\right)<w\left(s ; \sigma_{\epsilon m}\right)$ for all $s>\widehat{s}$. 
The proof is in Appendix A. ${ }^{14}$ The next proposition states that productivity is higher when the signal is more precise. This follows observing that expected ability is closer to the workers' signal when $\sigma_{\epsilon g}^{2}$ is smaller.

Proposition 2. Let $y_{g}\left(\sigma_{\epsilon g}\right)$ be the total production of workers from group $g$ when their signal's noise has standard deviation $\sigma_{\epsilon g}$. Production $y_{g}$ is decreasing in $\sigma_{\epsilon g}$.

For example, with the parameters used in Figure 1, and assuming that female workers are those with the larger signal noise variance $\left(\sigma_{\epsilon m}=1\right.$ and $\left.\sigma_{\epsilon f}=2\right), 24$ percent of males and 13.2 percent of females are employed in the complex job. Because there are fewer females than males in the right tail of the quality distribution conditional on any given signal, more females are mismatched, therefore males' total value of $(\log )$ production is equal to -0.29 , whereas females' is -0.35 . To assess the inefficiency cost arising from incomplete information, consider that if workers were efficiently assigned, the value of production would be 1.31 for each group.

\subsection{Heterogenous CEOs: Female and Male}

Consider now an environment in which some firms are managed by female CEOs and some by male CEOs. ${ }^{15}$ We assume that female CEOs are characterized by a better ability to assess the productivity of female workers, that is, female workers' signal is extracted from a more precise distribution, with noise variance $\sigma_{\epsilon F}^{2}<\sigma_{\epsilon f}^{2}$ (where the capital $\mathrm{F}$ denotes female workers when assessed by a female CEO, and lowercase $\mathrm{f}$ when assessed by a male CEO). Symmetrically, female CEOs evaluate male workers' with lower precision than male CEOs: $\sigma_{\epsilon M}^{2}>\sigma_{\epsilon m}^{2}$.

This assumption may be motivated by any difference in language, verbal and non-verbal communication styles and perceptions that may make it easier between people of the same gender to provide a better understanding of personal skills and attitudes, improve conflict resolutions, assignment to job-tasks, etc. A large sociolinguistic literature has found differences in verbal and non-verbal communication styles between groups defined by race or gender that may affect economic and social outcomes (see e.g. Dindia and Canary (2006) and Scollon et al. (2011)). ${ }^{16}$ Recent

\footnotetext{
${ }^{14}$ This "single-crossing" property of the wage functions of signals of different precision relies on assuming symmetry of the production function and of the signaling technology. However the result that a more precise signal implies higher wages at the top of the distribution, and lower wages at the bottom, is more general, and holds even if the wage functions cross more than once.

${ }^{15}$ We do not model the change in CEO gender or how the CEO is selected as we are interested in comparing differences in gender-specific wage distributions between firms where the top management has different gender.

${ }^{16}$ There exists also an extensive medical literature showing how physician-patient interactions are affected by the gender of both the physician and the patient (see Cooper-Patrick et al. (1999) Rathore et al. (2001), and Schmid Mast et al. (2007)).
} 
employee surveys also indicate that significant communication barriers between men and women exist in the workplace (Angier and Axelrod (2014), Ellison and Mullin (2014)). In the economics literature, several theoretical papers have adopted an assumption similar to ours. Lang (1986) develops a theory of discrimination based on language barriers between "speech communities" defined by race or gender. To motivate this assumption, Lang surveys the socio-linguistic literature demonstrating the existence of such communication barriers. Cornell and Welch (1996) adopt the same assumption in a model of screening discrimination. Morgan and Várdy (2009) discuss a model where hiring policies are affected by noisy signals of productivity, whose informativeness depends (as in our assumption) on group identity because of differences in "discourse systems". More recently, Bagues and Perez-Villadoniga (2013)'s model generates a similar-to-me-in-skills result where employers endogenously give higher valuations to candidates who excel in the same dimensions as them. This result can also provide a foundation to our assumption if female workers are more likely to excel on the same dimensions as female executives.

The equilibrium features described in Section 2.2 carry through in the environment with heterogenous CEOs. In this new environment we can compare the equilibrium wages and firm performance in firms with CEOs of different gender. Focus for example on the wage distributions of female workers. Figure 2 displays the wage distributions of female workers employed at firms with female or male CEOs. The distribution displayed by the dashed blue line was computed using a signal with noise variance $\sigma_{\epsilon f}^{2}=3$, representing draws from the (less precise) signals received by male CEOs; the distribution displayed by the solid red line was computed using a signal with noise variance $\sigma_{\epsilon F}^{2}=2$, representing draws from the (more precise) signals received by female CEOs. As stated in Proposition 1, Figure 2 shows that the wage distribution of female workers employed at female CEOs firms has thicker tails. ${ }^{17}$ Women working for a female CEO are more likely to be assigned to the complex task and they earn higher wages at same signals for all the signals above the single crossing reported in Figure 1. This generates the fatter right tail. Below the threshold corresponding to the single crossing, women working for a female CEO earn lower wages at same signal than women working for a male CEO because the female CEO has a better assessment of how low productivity really is in those cases. This generates the fatter left tail. The following prediction follows directly from Proposition 1:

Empirical implication 1. Wages of female workers in firms with female CEOs are

\footnotetext{
${ }^{17}$ Other parameters used in this simulation: $\sigma=1, \bar{q}=1, \mu=.5, h=1.1, l=1$. We picked these parameters to produce a graph that could show the qualitative features of the proposition.
} 


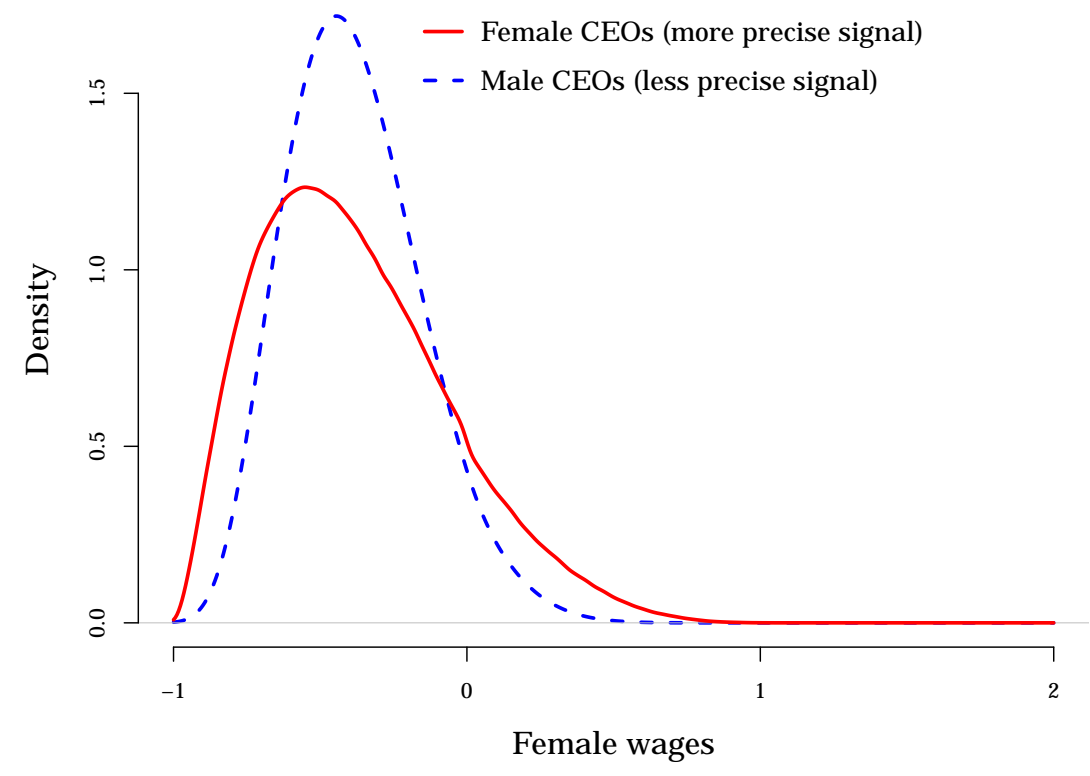

Figure 2: Simulation of the wage distributions of female workers

higher at the top of the wage distribution, and lower at the bottom of the wage distribution relative to wages of female workers employed by male CEOs. Symmetrically, wages of male workers in firms with female CEOs are higher at the bottom and lower at the top of the wage distribution relative to wages of male workers employed by male CEOs.

As a result, and as Figure 2 makes clear, we should also expect the variance of the wage distribution of female workers employed by female CEOs to be higher than the variance of the wage distribution of female workers employed by male CEOs. The opposite should be true on the variance of male wages.

The model has implications for firm performance as well. Proposition 2 states that total production is higher the lower the signal noise since CEOs can better match workers to jobs. As a result, we should observe that female CEOs can improve firm performance by implementing a better assignment of female workers. ${ }^{18}$ Therefore, we will test the following empirical prediction:

\footnotetext{
${ }^{18}$ Symmetrically, female CEO's assignment of male workers has the opposite effect. However, this effect might be weakened if female CEOs, upon assuming leadership, could "trust" the previous assignment of male workers made by a male CEO. We are agnostic about the details of job reassignment of workers of a different gender, which we do not model, and we focus on an implication that is robust to such details.
} 
Empirical implication 2. The productivity of firms with female CEOs increases with the share of female workers.

We derived Propositions 1 and 2 using specific distributional assumptions, but the empirical implications are robust to alternative distributions of the signal's noise and of the underlying productivity. A higher signal precision always implies less mismatching of workers to jobs, and a higher correlation of signals with productivity always implies lower wages when the signal is small and higher wages when the signal is high. These implications are also robust to alternative specifications of the signal extraction technology. In the online appendix (Flabbi et al. (2016b)), we derive the same empirical implications assuming a dynamic model where signals are extracted every period. Assuming all firms initially have male CEOs, firms acquiring female CEOs update the expected productivity of female workers with higher precision. The implications follow because female CEOs will rely on a larger number of more precise signals from female workers than male CEOs.

We do not model explicitly the selection process into executive positions (although in the empirical part we will take into account that such process might differ by gender) or how labor force dynamics are affected by CEO gender in a "general equilibrium". The change of a CEO's gender in our model will affect incentives for workers to leave the firm hoping to extract a more advantageous signal. Our results therefore assume rigidities in workforce mobility, which can be motivated by hiring and firing costs. However, the equilibrium wages by CEO and worker's gender derived in our propositions are nevertheless optimal and are indicative of the directions of wage changes we should expect when a CEO of different gender is appointed. ${ }^{19}$

\section{Data and Descriptive Statistics}

\subsection{Data Sources and Estimation Samples}

We use data from three sources that we label INVIND, INPS and CADS. From these three sources of data, we build a matched employer-employee panel data set and from this matched data set we extract our final estimation samples.

INVIND stands for the Bank of Italy's annual survey of manufacturing firms, an open panel of about 1,000 firms per year, representative of Italian manufacturing firms with at least 50 employees. INPS stands for the National Social Security Institute which provided the work histories of all workers ever employed at an

\footnotetext{
${ }^{19}$ This motivates in the empirical analysis the inclusion, in our benchmark specification, only of data from workers that were not hired after the new CEO was appointed. We check the robustness of our results to the inclusion of all workers.
} 
INVIND firm in the period 1980-1997, ${ }^{20}$ including spells of employment in firms not included in the INVIND survey. We match the INVIND firms with the INPS work histories thanks to unique worker and firms identifiers to create what we call the INVIND-INPS data set. This data set includes for each worker: gender, age, tenure $^{21}$, occupational status (production workers, non-production workers, executives), annual gross earnings (including overtime pay, shift work pay and bonuses), number of weeks worked, and a firm identifier. We exclude all records with missing entries on either the firm or the worker identifier, those for workers younger than 15, and those corresponding to workers with less than four weeks worked in a given year. For each worker-year, we kept only the observation corresponding to the main job (the job with the highest number of weeks worked). Overall, the INVIND-INPS data set includes information on about a million workers per year, more than half of whom are employed in INVIND firms in any given year. The remaining workers are employed in about 450,000 other companies of which we only know the firm identifier.

In Table 1 we report summary statistics on workers' characteristics for the INVIND-INPS data set. About $67 \%$ of observations pertain to production workers, $31 \%$ to non-production employees, and $2.2 \%$ to executives. Even though they represent about $21 \%$ of the workforce, women are only $2.5 \%$ of executives. On average, workers are 37 years old and have 5 years of tenure. Average gross weekly earnings at 1995 constant prices are around 388 euros, with women earning about $24 \%$ less than men (309 euros vs. 408 euros).

CADS, the third data source we use, stands for Company Accounts Data Service and includes balance-sheet information for a sample of about 40,000 firms between 1982 and 1997, including almost all INVIND firms. The data include information on industry, location, sales, revenues, value added at the firm-year level, and a firm identifier. Again thanks to a unique and common firm identifier, we can match CADS with INVIND-INPS.

Most of our empirical analysis focuses on the balanced panel sample consisting of firms continuously observed in the period 1988-1997. In Table 1 we report summary statistics both on this sample and on the entire, unbalanced INVIND-INPS-CADS sample for the same period. Notice that the unit of observation on the sample is a firm in a given year while in the INVIND-INPS was a worker in a given firm in

\footnotetext{
${ }^{20}$ The provision of these work histories data for the employees of the INVIND firms was done only once in the history of the data set and therefore can only cover firms and workers up to 1997. This is the reason why we cannot work on more recent data.

${ }^{21}$ Tenure information is left-censored because we do not have information on workers prior to 1981.
} 
Table 1: Descriptive statistics: INVIND-INPS sample and INVINDINPS-CADS sample

\begin{tabular}{|c|c|c|c|c|c|c|}
\hline & \multicolumn{2}{|c|}{ INVIND-INPS } & \multicolumn{4}{|c|}{ INVIND-INPS-CADS } \\
\hline & \multirow[b]{2}{*}{ Mean } & \multirow[b]{2}{*}{ Std.Dev. } & \multicolumn{2}{|c|}{$\begin{array}{l}\text { Unbalanced } \\
\text { panel }\end{array}$} & \multicolumn{2}{|c|}{$\begin{array}{c}\text { Balanced } \\
\text { panel }\end{array}$} \\
\hline & & & Mean & Std.Dev. & Mean & Std.Dev. \\
\hline$\%$ Prod. workers & 66.5 & & 67.6 & $(18.7)$ & 67.4 & $(18.3)$ \\
\hline$\%$ Non-prod. wrk & 31.3 & & 29.8 & $(17.7)$ & 30.0 & $(17.3)$ \\
\hline$\%$ Executives & 2.2 & & 2.5 & $(1.7)$ & 2.6 & $(1.8)$ \\
\hline$\%$ Females & 21.1 & & 26.2 & $(20.9)$ & 25.8 & $(20.1)$ \\
\hline$\%$ Fem. execs. & 2.5 & & 3.3 & $(10.3)$ & 3.4 & $(10.1)$ \\
\hline$\%$ Female CEO & & & 2.1 & & 1.8 & \\
\hline Age & 37.0 & $(10.1)$ & 37.2 & $(3.6)$ & 37.4 & $(3.4)$ \\
\hline Tenure & 5.1 & $(4.1)$ & 8.1 & $(2.6)$ & 8.7 & $(2.3)$ \\
\hline Wage (weekly) & 387.2 & $(253.8)$ & 400.3 & $(86.0)$ & 404.5 & $(88.7)$ \\
\hline Wage (males) & 408.1 & $(271.8)$ & 429.3 & $(92.7)$ & 433.9 & $(97.5)$ \\
\hline Wage (females) & 309.5 & $(146.6)$ & 343.3 & $(67.0)$ & 346.4 & $(68.5)$ \\
\hline Firm size (empl.) & & & 675.0 & $(2,628.6)$ & 704.2 & $(1,306.9)$ \\
\hline Sales ('000 euros) & & & 110,880 & $(397,461)$ & 118,475 & $(231,208)$ \\
\hline Sales/worker (ln) & & & 4.93 & $(0.62)$ & 4.95 & $(0.57)$ \\
\hline Val. add./wkr (ln) & & & 3.77 & $(0.43)$ & 3.79 & $(0.41)$ \\
\hline TFP & & & 2.49 & $(0.50)$ & 2.49 & $(0.49)$ \\
\hline N. Observations & 18 & 64,304 & & 029 & & 340 \\
\hline N. Firms & & 8,284 & & 95 & & 34 \\
\hline N. Workers & & 24,609 & & & & \\
\hline N. Years & & 17 & & 5 & & 10 \\
\hline
\end{tabular}

a given year. The unbalanced INPS-INVIND-CADS panel includes 5,029 firm-year observations from a total of 795 unique firms. Of these, 234 compose the balanced panel. In the unbalanced sample, average gross weekly earnings at 1995 constant prices are equal to about 405 euros. On average, workers are 37.2 years old and have 8 years of tenure. $68 \%$ of workers are blue collar, $30 \%$ white collar, and $2.5 \%$ are executives. The corresponding statistics in the balanced sample are very similar. 


\subsection{Female Leadership}

We identify female leadership from the job classification executive ${ }^{22}$ in the data. As already observed by Bandiera et al. (2011), one advantage of using data from Italy is that this indicator is very reliable because the job title of executive is subject to a different type of labor contract and executives are registered in a separate account with the social security administration agency (INPS). We identify the CEO as the executive with the highest compensation in a firm-year. This procedure is supported by the following: i) Salary determination in the Italian manufacturing sector is such that the compensation ordering follows very closely the hierarchical ranking within each of the three broad categories we observe (executives, non-production workers, production workers); ii) The firm's CEO is classified within the executive category; iii) We have a very detailed and precise measure of compensation because we have direct access to the administrative data that each firm is required by law to report (and that each worker has the incentive to verify is correctly reported); iv) We have access to all the workers employed by a given firm in a given year. ${ }^{23}$

Using these definitions, we find that although females are $26.2 \%$ of the workforce in INVIND firms, they are only $3.3 \%$ of the executives, and only $2.1 \%$ of CEOs. The descriptive statistics for the balanced panel are quite similar to those referring to the unbalanced sample and confirm the under-representation of women in top positions in firms found for other countries. In particular, the ratio between women in the labor force and women classified as executives is very similar to the ratio obtained from the ExecuComp ${ }^{24}$ data for the U.S.

Women's representation in executive positions in Italy has increased over time but remains small: In 1980, slightly above 10 percent of firms had at least one female executive, and females represented $2 \%$ of all executives and $1 \%$ of CEOs; In 1997, these figures were $20 \%, 4 \%$ and $2 \%$, respectively. There is substantial variation across industries in the presence of females in the executive ranks, but no obvious pattern emerges about the relationship between female leadership and the presence of females in the non-executive workforce in the various industries. ${ }^{25}$

\footnotetext{
${ }^{22}$ The original job description in Italian is dirigente, which corresponds to an executive in a US firm.

${ }^{23}$ We have the complete set of workers only for the INVIND firms and as a result we can only assign CEO's gender to INVIND firms. However, this is irrelevant for our final estimation sample at the firm level since for other reasons explained below we limit our main empirical analysis to a subset of INVIND firms. For another example in the literature using wage ranking to infer top managers, see Tate and Yang (2015).

${ }^{24}$ Execucomp is compiled by Standard and Poor and contains information on executives in the S\&P 500, S\&P MidCap 400, S\&P SmallCap 600. See for example, Bertrand and Hallock (2001), Wolfers (2006), Gayle et al. (2012), Dezsö and Ross (2012).

${ }^{25}$ See Table B1 in Flabbi et al. (2016b) for details.
} 


\section{Table 2: Descriptive statistics: Firms with Male and Female CEO in}

INVIND-INPS-CADS sample

\begin{tabular}{|c|c|c|c|c|}
\hline & \multicolumn{2}{|c|}{ Male CEO } & \multicolumn{2}{|c|}{ Female CEO } \\
\hline & Mean & St.Dev. & Mean & St.Dev. \\
\hline CEO's age & 49.5 & $(7.1)$ & 46.6 & $(7.1)$ \\
\hline CEO's tenure & 4.4 & $(3.7)$ & 4.0 & $(2.8)$ \\
\hline CEO's annual earnings & 199,385 & $(144,508)$ & 128,157 & $(54,643)$ \\
\hline$\%$ Production workers & 67.5 & $(18.7)$ & 75.4 & $(13.5)$ \\
\hline$\%$ Non-prod. workers & 30.0 & $(17.8)$ & 22.2 & $(13.1)$ \\
\hline$\%$ Executives & 2.5 & $(1.7)$ & 2.4 & $(1.4)$ \\
\hline$\%$ Females & 25.9 & $(20.7)$ & 37.2 & $(27.0)$ \\
\hline$\%$ Female executives & 2.4 & $(6.9)$ & 46.8 & $(29.5)$ \\
\hline \% Female executives (excl. CEO) & 3.3 & $(10.3)$ & 15.9 & $(28.6)$ \\
\hline Firm size (employment) & 683.7 & $(2,655.4)$ & 270.3 & $(409.9)$ \\
\hline Age & 37.2 & $(3.6)$ & 35.9 & $(3.5)$ \\
\hline Tenure & 8.1 & $(2.6)$ & 8.6 & $(2.2)$ \\
\hline Wage (earnings/week) & 401.6 & $(86.0)$ & 341.3 & $(61.7)$ \\
\hline Wage (males) & 430.6 & $(92.8)$ & 369.4 & $(64.2)$ \\
\hline Wage (females) & 343.3 & $(66.2)$ & 345.4 & $(97.1)$ \\
\hline Sales (thousand euros) & 112,467 & $(401,486)$ & 37,185 & $(55,982)$ \\
\hline Sales per worker $(\ln )$ & 4.9 & $(0.6)$ & 4.7 & $(0.6)$ \\
\hline Value added per worker $(\ln )$ & 3.8 & $(0.4)$ & 3.6 & $(0.4)$ \\
\hline TFP & 2.5 & $(0.5)$ & 2.4 & $(0.5)$ \\
\hline N. Observations & & 923 & & \\
\hline N. Firms & & 860 & & \\
\hline N. Years & & 15 & & \\
\hline
\end{tabular}

In Table 2 we compare firms with a male CEO with those with a female CEO. Firms with a female CEO are smaller, both in terms of employment and in terms of revenues, pay lower wages, and employ a larger share of blue collar workers. Firms with a female CEO also employ a larger share of female workers (37 vs. 26 percent). However, when one looks at measures of productivity (sales per employee, value added per employee, and TFP), the differences shrink considerably. For instance, total revenue is on average about 3 times higher in firms with a male CEO than in firms with a female CEO, but revenue per employee, value added per employee and TFP are only about 21 percent, 19 percent and 4 percent higher, respectively. 


\section{Empirical Analysis}

\subsection{Specification and Identification}

The unit of observation of our analysis is a given firm $j$ observed in a given year $t$. We are interested in the impact of female leadership on workers' wage distributions and firms' performance.

We will estimate regressions of the following form:

$$
y_{j t}=\beta F L E A D_{j t}+F I R M_{j t}^{\prime} \gamma+W O R K_{j t}^{\prime} \delta+E X E C_{j t}^{\prime} \chi+\lambda_{j}+\eta_{t}+\tau_{t(j)} t+\varepsilon_{j t}
$$

where: $y_{j t}$ is the dependent variable of interest, either moments of the workers' wage distribution or measures of firm performance, and $\beta$ is the coefficient of interest. The regressors and controls are defined as follows: $F L E A D_{j t}$ is the measure of female leadership used in the regression: either a female CEO dummy or the fraction of female executives; FIRM $M_{j t}$ is a vector of observable time-varying firm characteristics (dummies for size, industry, and region); $W O R K_{j t}$ is a vector of observable workforce characteristics aggregated at the firm-year level (age, tenure, occupation distribution, fraction female) plus worker fixed effects aggregated at the firm-year level and estimated in a "first step" regression described in detail below; $E X E C_{j t}$ is a vector of observable characteristics of the firm leadership used in the regression (age and tenure as CEO or executive) plus CEO's or executives' fixed effects estimated in the first step regression described in detail below; ${ }^{26} \lambda_{j}$ are firm fixed effects; $\eta_{t}$ are year dummies and $\tau_{t(j)}$ are industry-specific time trends.

The main challenge in estimating the impact of female CEOs (or female leadership in general) ${ }^{27}$ on workers' wages and firms' performance is the sample selection bias induced by the non-random assignment of CEOs to firms. In particular, it is possible that:

1. unobservable firm characteristics may make some firms more productive than others, and this unobserved firm-level component may not be randomly assigned between male- and female-led firms;

2. the workforce composition of firms led by women might systematically differ from that of firms led by men;

\footnotetext{
${ }^{26}$ When the female leadership measures is the female CEO dummy we simply use the CEO's value of the listed regressors; when the leadership measure is the proportion of female executives at the firms, we use the average of the listed regressors over the firm's executives.

${ }^{27}$ To simplify the discussion, we present the identification for the case in which female leadership is represented by the dummy female CEO. The same discussion carries through when we use the fraction of female executives as a measure of female leadership.
} 
3. the selection on unobserved individual ability in the position of CEO may not be the same by gender so that women CEOs may be of systematically higher or lower ability than men CEOs. As a result, female leadership indicators might be capturing such differences rather than gender effects.

Our strategy to address these issues is to control for firm fixed effects, workforce composition effects, and CEO effects. First, we include controls for a set of time-varying, observable firm characteristics, workforce characteristics, and CEO characteristics. Second, we control for time-invariant firm-level heterogeneity by estimating equation (4.1) with firm fixed effects both for wages and firm performance. Using within-firm variation to identify the impact of female leadership at the firm level has so far been the identification strategy most commonly employed in the literature. $^{28}$ Third, and new in the literature, we add controls for unobservable workforce and CEO heterogeneity obtained from a first step two-way fixed effects regression, as described next.

Our matched employer-employee data includes the entire work history (between 1980 and 1997) of all the workers who ever transited through one of our $J$ INVIND firms. This large matched employer-employee data set (almost 19 million worker-year observations) contains a large number of transitions of individuals across (INVIND and non-INVIND) firms and is thus well suited to estimate two-way fixed effects as in Abowd et al. (1999)(henceforth, AKM). An individual fixed effect estimated from such a regression has the advantage of controlling for the firms the worker or executive has ever worked for. As a result, it can capture those scale effects in individual productivity which are usually captured by education, other time-invariant human capital or other proxies for "ability" and skills. ${ }^{29}$

Our strategy is to use the individual fixed effects from an AKM regression to construct proxies for $\mathrm{CEO} /$ executive and average worker ability at the firm-year level to include as controls in regression 4.1. Specifically, we perform the two-way fixed effects procedure proposed by Abowd et al. (2002) by estimating the following equation:

$$
w_{i t}=\mathbf{s}_{i t}^{\prime} \beta+\eta_{t}+\alpha_{i}+\sum_{j=1}^{J} d j_{i t} \Psi_{j}+\zeta_{i t} .
$$

The dependent variable is the natural logarithm of weekly wages. The vector of

\footnotetext{
${ }^{28}$ See for example, Smith et al. (2006), Albanesi and Olivetti (2009), and Gagliarducci and Paser$\operatorname{man}(2015)$

${ }^{29}$ Including these controls as described in detail below also helps to alleviate the fact that our data set, as is frequently the case with administrative data, does not include a particularly rich set of controls at the individual worker level. For example, we have no measure of education or other formal training in the data which are usually included as controls in wage regressions.
} 
observable individual characteristics, $\mathbf{s}^{\prime}$, includes age, age squared, tenure, tenure squared, a dummy variable for non-production workers, a dummy for executives (occupational status changes over time for a considerable number of workers), as well as a full set of interactions of these variables with a female dummy (to allow the returns to age, tenure and occupation to vary by gender), and a set of year dummies. Our original sample consists of essentially one large connected group (comprising $99 \%$ of the sample). Thus, in our estimation we focus only on this connected group and disregard the remaining observations. The identification of firm effects and worker effects is delivered by the relatively high mobility of workers in the sample over the relatively long period under consideration: about 70 percent of workers have more than one employer during the 1980-1997 period, and between 8 and 15 percent of workers change employer in a given year. The $\hat{\alpha}_{i}$ obtained by this procedure for the firms' CEOs and executives are included in the vector $E X E C_{j t}$ to control for CEO's individual heterogeneity. Moreover, we also used them to compute the mean $\hat{\alpha}_{i}$ on the workers of a given firm $j$ in time $t$, which we then include among the controls for workforce composition $\left(W O R K_{j t}\right){ }^{30}$

The AKM method hinges on the assumptions of exogenous mobility of workers across firms conditional on observables. We follow Card et al. (2013) (CHK henceforth) in performing several tests to probe the validity of the assumption. ${ }^{31}$ We conclude that in our context, similarly to what found by CHK in the case of Germany, the additively separable firm and worker effects obtained from the AKM model can be taken as reasonable measures of the unobservable worker and firm components of wages. Tests and results are reported in detail in the Flabbi et al. $(2016 b){ }^{32}$

The three steps described above provide controls for: (i) time-varying, observable firm characteristics, workforce characteristics, and CEO characteristics; (ii) un-

\footnotetext{
${ }^{30}$ Under our model, the workers' wages from which we have estimated these worker fixed effects are affected by statistical discrimination. This does not introduce a bias in the estimate of the mean $\hat{\alpha}_{i}$ on the workers of a given firm $j$ in time $t$ because the model, as common in standard statistical discrimination models, does not imply "group discrimination". Moreover, the group of workers we have at each firm is large enough to deliver credible estimates: Our firms are relatively large by construction (firms are included in the INVIND sample only if they employ at least 50 employees) and the median number of workers in INVIND firms is around 250.

${ }^{31}$ Specifically, a model including unrestricted match effects delivers only a very modest improved statistical fit compared to the AKM model, and the departures from the exogenous mobility assumption suggested by the AKM residuals are small in magnitude. Moreover, wage changes for job movers show patterns that suggest that worker-firm match effects are not a primary driver of mobility in the Italian manufacturing sector. Instead, the patterns that we uncover are consistent with the predictions of the AKM model for job movers.

${ }^{32}$ The two-way fixed effect regressions generate expected results: wages exhibit concave age and tenure profiles, and there is a substantial wage premium associated with white collar jobs and, especially, with executive positions.
} 
observable time-invariant firm characteristics; and, (iii) unobservable time-invariant $\mathrm{CEO} /$ executive and average worker heterogeneity. These three steps constitute our preferred identification strategy and generate our benchmark specifications. In a fourth step, we provide extensive robustness analyses. Specifically, we address the robustness of our estimation results with respect to: the inclusion of workers hired by the new CEOs; separate impacts of being a newly nominated CEO; exit and entry of firms; different measures of female leadership and firm performance; and unobservable time-varying firm-level shocks potentially correlated with the CEO's gender. This last robustness exercise is conducted by building novel instruments applying Bartik's seminal idea (Bartik (1991)) to our firm-level analysis.

The estimation of equation (4.1) for the various dependent variables of interest is presented in Section 4.2 and 4.3. All regressions share the same baseline specification which includes firm fixed-effects, time-varying firm controls, workforce composition controls and controls for CEOs' characteristics. Specifically, the complete set of controls is: $\mathrm{CEO}$ age, tenure as CEO, CEO fixed effects computed in the 2-way fixed-effects regression described above, the fraction of non-executive female workers, the fraction of non-production workers, the mean age of the workforce, the average of workers' fixed effects computed in the 2-way AKM fixed-effects regression, a set of 15 region dummies, 20 industry dummies, 4 firm-size dummies, year dummies, and industry-specific time trends. Notice that the firm fixed effects also control for the firms'ownership type, which for the vast majority of the companies in our sample does not change over time. ${ }^{33}$

\subsection{Female Leadership and Firm-Level Workers Wages Distributions}

In the model we presented in Section 2, female CEOs extract more precise signals of productivity from female workers. A more precise signal implies that women at the top of the wage distribution should earn higher wages than females at the top of the distribution employed by male CEOs. Women at the bottom of the wage distribution, on the other hand, should earn lower wages when employed by female

\footnotetext{
${ }^{33}$ There are four types of firms in our dataset: family firms, conglomerates, foreign/institution owned and government owned. The presence of female executives appears to be similar across ownership types, with the exception of government owned firms, where female executives are almost non-existent (government-owned firms are lessn than $5 \%$ of the sample). In the full sample, women are $3.3 \%$ of executives in family firms, $2.4 \%$ in conglomerates, and $3.3 \%$ in foreign/institution-owned firms. The proportions of firm-year observations with a female CEO is $1.8 \%$ among family firms, $1.2 \%$ among conglomerates, and $1.1 \%$ among foreign/institution-owned firms. In the balanced panel, proportions are also relatively stable with, respectively, $4.6 \%, 2.8 \%$ and $5.5 \%$ of female executives and $3.0 \%, 1.5 \%$ and $2.7 \%$ of female CEOs.
} 
Figure 3: Coefficients of female CEO dummy on average wages by quantile of the female and male wage distributions

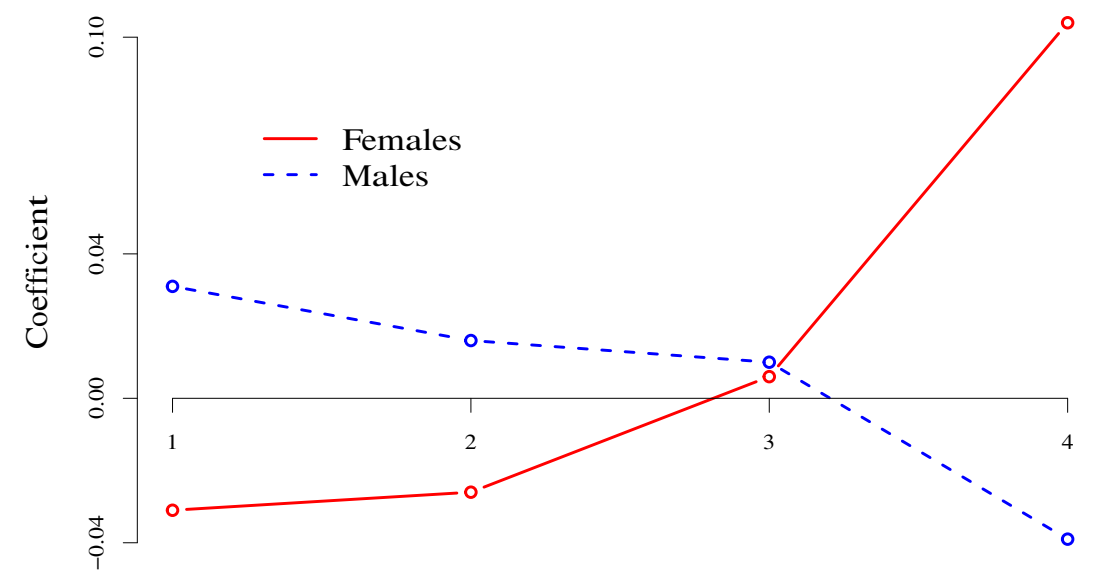

Quantiles

CEOs. As a result, the overall wage dispersion of female workers in each firm should be higher in firms managed by women CEOs.

\subsubsection{Results}

Motivated by this prediction, we estimate equation (4.1) using as dependent variables $y_{j t}$ a set of firm- and gender-specific moments of the workers' wages distribution: the standard deviation, average wages below and above the median, below the 10th and above the 90th percentile, and average wages within each quartile of the wage distribution. Our main regressor of interest is the measure of female leadership: a female CEO dummy or the share of female executives. As described in Section 4.1, all regressions include firm fixed-effects, time-varying firm controls, workforce composition controls and controls for CEOs' characteristics.

Figure 3 summarizes our main results by reporting the estimated coefficients on the female CEO dummy on the four quartiles of the wage distribution using our benchmark specification. The red continuous line shows that female leadership has a positive effect on female wages at the top of the distribution and a negative effect at the bottom of the distribution. The effect on the male wage distribution, illustrated by the blue dashed line, is symmetric and of the opposite sign. The effects are consistently increasing, moving from the bottom to the top of the female wage distribution, whereas they are decreasing moving from the bottom to the top the 
male distribution. These results conform to Empirical prediction 1 of Section 2 .

To provide details on the precision and robustness of these results, we report the estimated effects of female leadership on various moments of the female wage distribution in Table 3 and of the male wage distribution in Table 4, according to six different specifications (panels (a) through (g)). ${ }^{34}$ Coefficient estimates for the more relevant controls for the benchmark specification are reported in the Appendix, and for the other specifications in the Web Appendix.

Panel (a) reports the results of our benchmark specification, where the measure of female leadership is a dummy variable indicating whether the firm is managed by a female CEO. This specification is estimated using the balanced sample to avoid the selection of firms entering and exiting the sample. To eliminate possible confounding effects induced by workers being hired or leaving after the appointment of the female CEO, we used only observations on workers hired under the previous CEO and who stay at the firm during the female CEO's tenure. Other specifications show that this sample selection and choice of variables do not significantly affect our results.

For each specification, the tables report the estimated coefficient on the measure of female leadership. In addition, because our model makes specific predictions on the effects of female leadership on the wage variance, and on wages at the top and bottom of the gender-specific wage distributions, we report the p-values of 1-tailed tests of the model's predictions. ${ }^{35}$ Specifically, we test the null hypothesis that female leadership has zero impact on the dependent variable against different alternatives specified according to the predictions of the model. That is, we test against the alternative hypothesis that female leadership has a positive impact on the variance of female wages, a positive impact at the top of the female wages distribution and a negative impact at the bottom. On the corresponding moments of the male wage distribution, the alternative hypothesis is that the impact of female leadership has the opposite signs. Top and bottom are defined as above and below the median. ${ }^{36}$

\footnotetext{
${ }^{34}$ Dependent variables in columns (4)-(9) are defined as follows: Decile 1 (column 4): average wage of earners below the 10th percentile of the wage distribution. Decile 10 (column 5): average wage of earners above the 90th percentile. Quantile 1: average wages below the 25th percentile; Quantile 2: average wages between the 25th and 50th percentile; Quantile 3: average wages between the 50th and the 75th percentile; Quantile 4: average wages above the 75th percentile of the wage distribution.

${ }^{35}$ Given that individual CEO effects are generated regressors from a first step estimation, in all specifications except (f)-(h), P-values are computed using bootstrapped standard errors with 300 replications. As described in detail in the Appendix, our bootstrapping procedure resamples firms, stratifying by firms that never had a female CEO and firms that had a female CEO. In specification (f)-(h), standard errors are clustered at the firm level. Standard errors are reported in the Appendix for the benchmark specification and in the Web Appendix (Flabbi et al. (2016b)) for the other specifications.

${ }^{36}$ Note that the theory predicts that the effects of female leadership should be positive or negative at the top or bottom but does not predict non-parametrically where the change of sign should occur.
} 


\section{Table 3: Impact of female leadership on moments of the firm-level female wage distributions}

\begin{tabular}{|c|c|c|c|c|c|c|c|c|c|}
\hline \multirow{4}{*}{$\begin{array}{c}\text { Dependent } \\
\text { variable: }\end{array} \rightarrow$} & \multirow{4}{*}{$\begin{array}{l}\text { Std. } \\
\text { dev. } \\
(1)\end{array}$} & \multicolumn{8}{|c|}{ Average wages } \\
\hline & & \multicolumn{2}{|c|}{ Median } & \multicolumn{2}{|c|}{ Decile } & \multicolumn{4}{|c|}{ Quantiles } \\
\hline & & Below & Above & 1 & 10 & 1 & 2 & 3 & 4 \\
\hline & & $(2)$ & $(3)$ & (4) & $(5)$ & (6) & $(7)$ & $(8)$ & (9) \\
\hline \multicolumn{10}{|c|}{ (a) Benchmark } \\
\hline Coefficient & 0.475 & -0.030 & 0.078 & -0.043 & 0.167 & -0.031 & -0.026 & 0.006 & 0.104 \\
\hline 1-tail P-value & 0.000 & 0.090 & 0.003 & 0.124 & 0.004 & 0.147 & 0.112 & 0.424 & 0.001 \\
\hline \multicolumn{10}{|c|}{ (b) All workers } \\
\hline Coefficient & 0.418 & -0.032 & 0.049 & -0.038 & 0.121 & -0.036 & -0.027 & -0.020 & 0.072 \\
\hline 1-tail P-value & 0.000 & 0.041 & 0.062 & 0.146 & 0.009 & 0.108 & 0.043 & 0.824 & 0.027 \\
\hline \multicolumn{10}{|c|}{ (c) With controls for new CEO } \\
\hline Coefficient & 0.477 & -0.030 & 0.079 & -0.043 & 0.168 & -0.030 & -0.026 & 0.007 & 0.105 \\
\hline 1-tail P-value & 0.000 & 0.090 & 0.003 & 0.124 & 0.004 & 0.148 & 0.112 & 0.410 & 0.001 \\
\hline \multicolumn{10}{|c|}{ (d) Full panel } \\
\hline Coefficient & 0.403 & -0.016 & 0.073 & -0.004 & 0.170 & -0.007 & -0.022 & 0.006 & 0.096 \\
\hline 1-tail P-value & 0.000 & 0.206 & 0.000 & 0.448 & 0.000 & 0.390 & 0.121 & 0.370 & 0.000 \\
\hline
\end{tabular}

(e) Different measure of female leadership: fraction of female executives

\begin{tabular}{r|c|cc|cc|cccc} 
Coefficient & 2.108 & -0.036 & 0.310 & -0.114 & 0.789 & -0.053 & -0.022 & -0.007 & 0.421 \\
1-tail P-value & 0.000 & 0.188 & 0.000 & 0.109 & 0.000 & 0.172 & 0.286 & 0.571 & 0.000
\end{tabular}

(f) Without controls for unobservable workforce and CEO ability

\begin{tabular}{r|c|cc|cc|cccc} 
Coefficient & 0.460 & -0.035 & 0.072 & -0.045 & 0.159 & -0.035 & -0.032 & 0.001 & 0.097 \\
1-tail P-value & 0.000 & 0.037 & 0.009 & 0.086 & 0.007 & 0.093 & 0.051 & 0.481 & 0.004
\end{tabular}

\begin{tabular}{r|c|cc|cc|cccc} 
& (g) IV on specification (f) \\
Coefficient & 0.948 & -0.096 & 0.059 & -0.441 & 0.165 & -0.213 & -0.018 & -0.018 & 0.067 \\
1-tail P-value & 0.000 & 0.111 & 0.287 & 0.015 & 0.194 & 0.023 & 0.387 & 0.618 & 0.315
\end{tabular}

\begin{tabular}{r|c|cc|cc|cccc}
\multicolumn{1}{c}{ (h) IV on specification (f) and (e) combined } \\
Coefficient & 1.464 & -0.162 & 0.075 & -0.666 & 0.243 & -0.333 & -0.047 & -0.043 & 0.088 \\
1-tail P-value & 0.000 & 0.066 & 0.333 & 0.002 & 0.216 & 0.009 & 0.306 & 0.680 & 0.350
\end{tabular}

Firms fixed-effects regressions. Dependent variables are in logs. Dependent variables in columns (4-9) are defined in Footnote 34. Coefficients for a larger set of explanatory variables and standard errors are reported in Appendix and the online appendix (Flabbi et al. (2016b)). Number of observations: 2,340 (234 Firms, 10 years), all specifications except (d); specification (d): 5,029 observations (795 firms). P-values are computed using bootstrapped standard errors with 300 replications in (a)-(e) and by standard errors clustered at the firm level in (f)-(h). 


\section{Table 4: Impact of female leadership on moments of the firm-level male wage distributions}

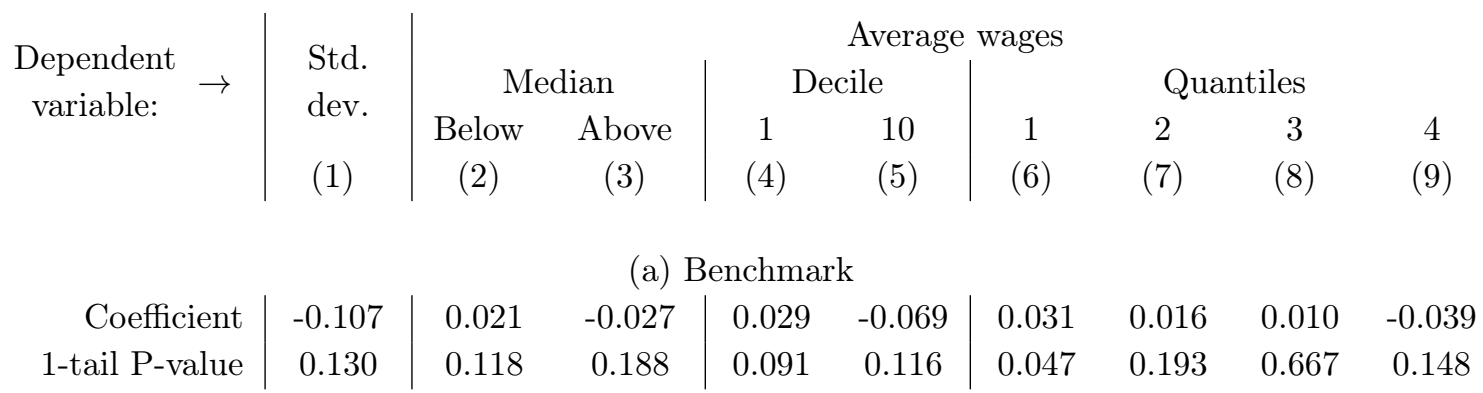

\begin{tabular}{r|c|cc|cc|cccc} 
& \multicolumn{1}{c}{ (b) All workers } \\
Coefficient & -0.113 & -0.016 & -0.037 & -0.023 & -0.071 & -0.016 & -0.015 & -0.014 & -0.047 \\
1-tail P-value & 0.095 & 0.894 & 0.080 & 0.919 & 0.078 & 0.901 & 0.870 & 0.183 & 0.076
\end{tabular}

\begin{tabular}{r|c|cc|cc|cccc}
\multicolumn{1}{c}{ (c) With controls for new CEO } \\
Coefficient & -0.105 & 0.022 & -0.027 & 0.029 & -0.067 & 0.031 & 0.016 & 0.010 & -0.039 \\
1-tail P-value & 0.133 & 0.115 & 0.194 & 0.090 & 0.120 & 0.046 & 0.188 & 0.670 & 0.153
\end{tabular}

\begin{tabular}{r|c|cc|cc|cccc}
\multicolumn{1}{c}{ (d) Full panel } \\
Coefficient & -0.152 & 0.030 & -0.038 & 0.058 & -0.092 & 0.049 & 0.019 & 0.005 & -0.054 \\
1-tail P-value & 0.021 & 0.002 & 0.069 & 0.000 & 0.035 & 0.000 & 0.038 & 0.630 & 0.049
\end{tabular}

(e) Different measure of female leadership: fraction of female executives

\begin{tabular}{r|c|cc|cc|cccc} 
Coefficient & -0.232 & 0.008 & -0.091 & -0.024 & -0.203 & -0.004 & 0.016 & 0.004 & -0.128 \\
1-tail P-value & 0.132 & 0.409 & 0.067 & 0.648 & 0.039 & 0.539 & 0.303 & 0.550 & 0.048
\end{tabular}

(f) Without controls for unobservable workforce and CEO ability

\begin{tabular}{r|c|cc|cc|cccc} 
Coefficient & -0.187 & 0.018 & -0.043 & 0.023 & -0.104 & 0.026 & 0.013 & 0.007 & -0.060 \\
1-tail P-value & 0.013 & 0.154 & 0.059 & 0.148 & 0.027 & 0.077 & 0.231 & 0.629 & 0.037
\end{tabular}

\begin{tabular}{r|c|cc|cc|cccc}
\multicolumn{1}{c}{ (g) IV on specification (f) } \\
Coefficient & -0.342 & 0.078 & -0.054 & 0.075 & -0.142 & 0.076 & 0.077 & 0.054 & -0.093 \\
1-tail P-value & 0.063 & 0.019 & 0.258 & 0.131 & 0.167 & 0.037 & 0.047 & 0.846 & 0.178
\end{tabular}

(h) IV on specification (f) and (e) combined

\begin{tabular}{r|c|cc|cc|cccc} 
Coefficient & -0.559 & 0.103 & -0.101 & 0.090 & -0.246 & 0.095 & 0.102 & 0.071 & -0.162 \\
1-tail P-value & 0.030 & 0.040 & 0.208 & 0.226 & 0.117 & 0.119 & 0.049 & 0.832 & 0.138
\end{tabular}

Firms fixed-effects regressions. Dependent variables are in logs. Dependent variables in columns (4-9) are defined in Footnote 34. Coefficients for a larger set of explanatory variables and standard errors are reported in Appendix and the online appendix (Flabbi et al. (2016b)). Number of observations: 2,340 (234 Firms, 10 years), all specifications except (d); specification (d): 5,029 observations (795 firms). P-values are computed using bootstrapped standard errors with 300 replications in (a)-(e) and by standard errors clustered at the firm level in (f)-(h). 
The results on the benchmark specification (row (a)) show that:

(i) Female leadership has a strong, economically and statistically significant positive effect on the variance of women's wages, as predicted by the theory. The standard deviation of female wages is almost $50 \%$ larger when the firm is managed by a female CEO. The effect on the male wage variance is also strong (about 10\%) and, as predicted by our model, of the opposite sign, but less precisely estimated.

(ii) The effect of female leadership on wages at the top of the female wage distribution (columns 3,5, and 9) is strongly positive and statistically significant, with P-values of less than $1 \%$. Females with wages above the median earn on average $7.8 \%$ more when working for a female CEO than for male CEOs (Table 3, column 3). The effect of female leaderships is stronger at the right end of the wage distribution: the (highly significant) positive impact of female leadership is $10.4 \%$ for females with wages above the 25 th percentile (column 9) and $16.7 \%$ for those earning above the 10th percentile (column 5). Symmetrically, the effect of female leadership on wages at the bottom of the male wage distribution (Table 4, columns 2, 4, 6, and 7) is positive and significant at levels close or below the $10 \%$ level.

(iii) The effect of female leadership is monotonically increasing moving from the bottom to the top of the female wage distribution (compare the estimates of columns 2 and 3,4 and 5, and of columns 6 through 9). The opposite holds true for the effect on male wages. This is the result illustrated in Figure 3.

(iv) The effect of female leadership at the bottom of the female wage distribution (columns (2), (4), and (6)) is negative and large across all specifications, although it is less precisely estimated than the effects at the top of the wage distribution.

(v) The estimates on the third quantile of the wage distribution (column 8 in both tables) do not reject the hypothesis that the coefficients are zero. This is still consistent with the theory, which predicts that the effects of female leadership should be zero somewhere in the interior of the wage distribution, but does not predict nonparametrically where the change of sign should occur.

\subsubsection{Robustness}

We describe here robustness analyses of the results. To ease the comparison, results are reported in the same tables (3 and 4 ).

We first address the sensitivity of our results to excluding workers hired by the female CEO. Since we do not explicitly model selection of workers or hiring decisions, our benchmark specification only included workers hired under the previous CEO

Therefore, choosing the median is arbitrary. This is the reason why we add other possible cuts to the wage distribution: top and bottom $10 \%$ and quartiles. 
and who stayed at the firm during the female CEO's tenure. Panel (b) presents results after removing this restriction, i.e. including in the sample workers hired by the new CEO. On the female samples (Table 3), there is only a small decrease in the magnitude of the effects at the top of the distribution. On the male samples, point estimates have the same sign and similar magnitudes, but we lose significance at the bottom of the distribution.

The second concern relates to the treatment effect we are trying to identify. A firm changing from being led by a male CEO to a female CEO implies a change of CEO. The effect that we are estimating could be due to the change of leadership rather than to the change in the leadership's gender. In panel (c) all the regressions include an additional control for whether the CEO was recently appointed. Results are almost identical to those from the benchmark specification.

The third concern relates to the selection of firms. In the benchmark specification we focus on a balanced panel sample since we do not explicitly model entry and exit of firms and the data do not specify whether firms no longer in the data were liquidated or acquired. Panel (d) reports the results on the full (unbalanced) panel. The estimation sample changes substantially and the sample size increases significantly: from 234 firms observed over 10 years in the balanced panel, to 795 firms observed over a maximum of 10 years for a total of 5,029 observations. Despite this major change in the estimation sample, most results are very similar to the benchmark specification. The estimates at the bottom of the female distribution are less precise and have smaller magnitudes than in the benchmark, but they maintain the expected sign.

The fourth concern refers to the measure of female leadership we use. The CEO's gender is an important measure of female leadership, it has been used in previous literature and it fits well with our theoretical model. However, the identification hinges on the relatively small number of firms experiencing a switch in CEO's gender. We use the proportion of female executives at the firm to evaluate the impact of a leadership measure displaying more variation than the female CEO dummy. Results are presented in panel (e). On the female sample, all the signs are consistent with the benchmark specification, the estimates are very precise on the regressions on the standard deviation and the top of the wage distribution whereas they have P-values slightly higher than 0.1 in the regressions at the bottom of the wage distribution. On the male sample, the bottom decile and quantile show the wrong sign, but the coefficients are very imprecisely estimated. All of the other estimates are consistent with the benchmark.

The fifth robustness check is about the calculation of the standard errors. All of 
our specifications include generated regressors (the workers' and CEOs' fixed effect obtained from the two-way fixed effects regression). For this reason (and since we do not have an expression for the variance and covariance matrix from the AKM procedure), we have bootstrapped the standard errors. Panel (f) reports results from a specification which does not include the generated regressors so that we can compute standard errors clustered at the firm level in the conventional way. All of the estimates have the expected sign and comparable magnitudes. With respect to the benchmark, P-values are generally smaller on the female sample and at the top of the distribution of the male sample, and higher at the bottom of the male sample.

The sixth robustness exercise accounts for potential endogeneity induced by timevarying firm-level shocks. For example, a significant change to unobservable traits such as "corporate culture" may lead to the appointment of a female CEO, but also directly impact wages and performance. Such shocks cannot be controlled for by the firm fixed-effects we have in our specifications because they are time-invariant. To address this problem we construct a set of instruments inspired by Bartik (1991). The instruments exploit aggregate growth in the proportion of female executives at the region-year level. ${ }^{37}$ We assume that aggregate trends in female leadership are exogenous with respect to the time-varying firm-level heterogeneity we are concerned about, but they are potentially co-moving with actual firm-level values once we apply aggregate growth rates to firm-specific initial conditions (recall that the endogeneity of firm-specific initial conditions is controlled for by firm fixed-effects.) The firmspecific initial conditions we use are the proportion of female executives and the predicted probability of having a female CEO in a given base year for a firm. The instruments are built applying aggregate growth rates to these base-year values. A detailed explanation of the instruments' construction is provided in Appendix C. ${ }^{38}$

Results are reported in Panels (g) and (h). Panel (g) reports IV results on specification (f), i.e. the specification without the generated regressors obtained from the two-way fixed effects regression. We prefer to avoid generated regressors in our IV firm fixed-effects procedure in order to use conventional statistics to evaluate the first stage and compute standard errors. Panel (h) reports IV results on a specification without generated regressors but uses the other measure of female leadership: fraction of female managers. The first stages of our IV procedure do not indicate the presence of weak instruments problems. ${ }^{39}$ Yet, they explain a limited amount of

\footnotetext{
${ }^{37}$ There are a total total of 21 regions in our data.

${ }^{38}$ Due to data limitations, the base year we consider is 1988 , the first year of the estimation panel data. We have experimented with earlier base years but the loss of observations in the balanced panel became quickly too severe. The predicted probability of having a female CEO in a given base year is based on a firm-year level probit

${ }^{39}$ See the Appendix and the online appendix (Flabbi et al. (2016b)).
} 
variation. This issue, coupled with the already relatively small number of identifying observations, leads to larger standard errors and higher P-values in most of our IV regressions. Only the regressions on the standard deviation and on the bottom of the wage distribution for women deliver P-values within the range of conventional significance levels. If the IV estimates are imprecise, the sign and magnitude are entirely in line with our benchmark specifications. This is true both in the specifications using female CEO as the measure of female leadership and in those using the fraction of female executives. It also holds both on the regressions using the female wage distribution and on those using the male wage distribution.

\subsubsection{Summing up}

To summarize, the point estimates' signs of the differential impact of female leadership over the wage distribution are consistent with the prediction of our theoretical framework. These effects are strong and robust across specifications. They are also strongly statistically significant when predicted to be positive, with the exception of the IV specifications. When they are predicted to be negative, the estimates that we obtain are close to and often below conventional levels of statistical significance.

Despite the lack of strong statistical significance at the bottom of the wage distributions in some specifications, we argue that the results are remarkably consistent with our proposed mechanism. There are at least four factors that support this claim. First, the sign of the point estimates is consistent across specifications. In particular, results are robust to extending the data to include the full panel of firms, and to including all workers (not just those that were employed at the time the female CEO took charge of the firm). They are also robust to excluding the generated regressors computed in the two-way fixed-effects regression. In this case, the point estimates are more precisely estimated even though the reported standard errors are clustered at the firm level. As expected, the IV estimates are more imprecise, but signs and magnitudes are in line with benchmark specifications. Second, the effects are generally stronger at the extremes of the distribution, as one can observe by comparing the extreme deciles to the first and fourth quartiles. A stronger impact at the extremes is predicted by our model, as made clear by Figure 2 in Section 2. Third, the effects are increasing from the left to the right of the female wage distribution, consistent with the theory. The opposite occurs on the male wage distribution. Finally, downward wage rigidity works against finding large negative effects at the bottom of the wage distribution. It is therefore possible that the lower precision of the estimates at the the bottom is more related to ignoring institutional factors that may reduce downward wage adjustments than to a significant violation of the 
mechanism we propose.

\subsection{Female Leadership and Firm-Level Performance}

This section is motivated by the second Empirical Implication of our theoretical framework. Female executives improve the allocation of female talents within the firm by counteracting pre-existing statistical discrimination from male executives. We expect the efficiency-enhancing effects of female leadership to be stronger the larger the presence of female workers.

\subsubsection{Results}

Table 5 presents the estimation results from firm performance regressions, i.e. coefficients from estimating equation (4.1) where the dependent variable $y_{j t}$ is one of the three measures of firm performance: sales per employee, value added per employee, and TFP. ${ }^{40}$ The female leadership measures and the controls are the same as those used in the wage regressions. As in the previous subsection, our benchmark specification focuses on the balanced panel of firms that were continuously observed from 1988 through 1997 (panel (a) in the table). The other panels report results from our robustness analysis and they are discussed in section 4.3.2. In Table 5 we report the coefficients only on the variables of interest for our results. The Appendix reports the set of estimated coefficients for the other main explanatory variables.

Columns 1, 3, and 5 present specifications without interacting the female leadership variable with the share of females in the firm's workforce, and confirm previous results from the literature: as found by Smith et al. (2006), Albanesi and Olivetti (2009), and Gagliarducci and Paserman (2015) ${ }^{41}$ female executives do not have a significant impact on firm performance once one controls for firm fixed effects. ${ }^{42}$

However, when we change the specification in order to assess Empirical Implication 2 from our model, results are different. Columns 2, 4, and 6 of Table 5 report the estimated coefficients from specifications where the measure of female leadership is interacted with the proportion of non-executive female workers at the firm. ${ }^{43}$ Our model predicts a positive effect of this interaction because female CEOs improve

\footnotetext{
${ }^{40}$ We computed TFP using the Olley and Pakes (1996). See Iranzo et al. (2008) for details.

${ }^{41}$ Recent work on the impact of gender quotas for firms' boards have found a negative impact on short-term profits (Ahern and Dittmar (2012), Matsa and Miller (2013)). However, first, these papers consider the composition of boards, not executive bodies; second, it is not clear whether the impact is due to imposing a constraint on the composition of the board or to the fact that the added members of the boards are female.

${ }^{42}$ The only exception is TFP reporting a marginally significant negative impact.

${ }^{43}$ Just as in the wage regressions, we only focus on non-executives because the theory presented in Section 2 is not modeling promotion to executive, executive pay or interaction within executives.
} 
Table 5: Impacts of female leadership on firm-level performance

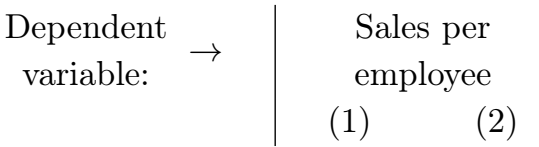

\author{
Value added \\ per employee \\ (3) \\ (4)
}

TFP

(5) (6)

\begin{tabular}{l|cc|cc|cc}
\multicolumn{7}{c}{ (a) Benchmark } \\
Female leadership & 0.033 & -0.120 & -0.046 & -0.245 & -0.059 & -0.213 \\
Std. Error & $(0.039)$ & $(0.045)$ & $(0.038)$ & $(0.041)$ & $(0.029)$ & $(0.039)$ \\
Interaction & & 0.610 & & 0.795 & & 0.616 \\
1-tail P-value & & 0.007 & & 0.003 & & 0.019
\end{tabular}

(b) Full Panel

\begin{tabular}{l|cc|cc|cc} 
Female leadership & 0.029 & -0.009 & -0.049 & -0.093 & -0.061 & -0.096 \\
Std. Error & $(0.024)$ & $(0.034)$ & $(0.026)$ & $(0.032)$ & $(0.024)$ & $(0.031)$ \\
Interaction & & 0.123 & & 0.144 & & 0.115 \\
1-tail P-value & & 0.066 & & 0.022 & & 0.041
\end{tabular}

(c) Different measure of female leadership: fraction of female executives

\begin{tabular}{l|cc|cc|cc} 
Female leadership & 0.025 & -0.322 & -0.208 & -0.429 & -0.236 & -0.413 \\
& $(0.098)$ & $(0.194)$ & $(0.119)$ & $(0.221)$ & $(0.126)$ & $(0.238)$ \\
Interaction & & 1.098 & & 0.697 & & 0.559 \\
1-tail P-value & & 0.007 & & 0.083 & & 0.146
\end{tabular}

(d) Without controls for unobservable workforce and CEO ability

\begin{tabular}{l|cc|cc|cc} 
Female leadership & 0.027 & -0.104 & -0.064 & -0.234 & -0.072 & -0.200 \\
Std. Error & $(0.061)$ & $(0.071)$ & $(0.058)$ & $(0.057)$ & $(0.045)$ & $(0.051)$ \\
Interaction & & 0.523 & & 0.677 & & 0.513 \\
1-tail P-value & & 0.001 & & 0.000 & & 0.002
\end{tabular}

(e) IV on specification (d)

\begin{tabular}{l|cc|cc|cc} 
Female leadership & 0.212 & -0.131 & -0.219 & -1.174 & -0.399 & -1.701 \\
& $(0.159)$ & $(0.452)$ & $(0.279)$ & $(0.773)$ & $(0.352)$ & $(1.118)$ \\
Interaction & & 0.645 & & 1.821 & & 2.472 \\
1-tail P-value & & 0.165 & & 0.064 & & 0.076
\end{tabular}

(f) IV on specification (d) and (c) combined

\begin{tabular}{l|cc|cc|cc} 
Female leadership & 0.292 & -0.218 & -0.323 & -1.336 & -0.593 & -1.887 \\
& $(0.263)$ & $(0.517)$ & $(0.358)$ & $(0.859)$ & $(0.427)$ & $(1.241)$ \\
Interaction & & 1.051 & & 2.087 & & 2.668 \\
1-tail P-value & & 0.080 & & 0.067 & & 0.086
\end{tabular}

Firms fixed-effects regressions. Female leadership: Female CEO dummy (panels a, b, d, e); Fraction of female executives (panel c, f); Interaction: female leadership interacted with the fraction of female workers (non-executive). Coefficients for a larger set of explanatory variables and standard errors are reported in Appendix B and in the online appendix (Flabbi et al. (2016b)). P-values are computed using bootstrapped standard errors with 300 replications in (a)-(c) and by standard errors clustered at the firm level in (d)-(f). 
firm performance by better allocating female workers. The higher the proportion of women, the higher the potential for gains in reallocation. Consistently with this prediction, we find a positive and significant coefficient on the interaction variable for each of the three measures of firm performance. The magnitude of the impact is substantial: for example, looking at column (2) we see that a female CEO taking over a firm employing the average proportion of women in the sample (about 25\%) would increase sales per employee by about $3.2 \%$; if half of the firm's workers were women the impact would be about $18.5 \%$.

\subsubsection{Robustness}

As in the wage regressions section, we provide a robustness analysis of the results presented in the benchmark specification. They are reported in panels (b) to (f) and address the same set of concerns.

Panel (b) reports results obtained using the full (unbalanced) panel. Again, the change in the estimation sample is substantial but the main effects still hold. The interaction term registers a positive effect, even if the magnitude is smaller and the estimates more imprecise but still significant.

Panel (c) reports results using the proportion of female executives as a measure of female leadership. We estimate an economically significant positive effect. The estimated effect is statistically significant for Sales and Value Added per employee, whereas it is not significant for TFP.

Panel (d) is obtained from regressions that do not include the generated regressors in order to avoid the computation of the standard errors by bootstrap. The point estimates are of a similar order of magnitude and the P-values rejecting a negative effect on the interaction are even stronger than in the benchmark specifications.

Panels (e) and (f) report estimates obtained from firm fixed effects IVs using the same instruments used in section 4.2.2 and described in details in the Appendix. The main results of the benchmark specification are confirmed both on regressions using female CEO as measure of female leadership and on regressions using fraction of female executives. The interaction is positive on all specifications and the magnitude is generally larger than on the benchmark, in particular on TFP. The 1-tail test rejects a negative impact at conventional levels on all specifications with the exception of female CEO on sales per employee. In this case the P-value is slightly above $10 \%$ registering a value of 0.165 . 


\subsubsection{Summing up}

Empirical Prediction 2 in our model implies that the productivity of firms with female leadership should increase with the share of female workers. We asses this prediction by introducing an interaction term in firm fixed effects regressions which use three measures of firm performance as dependent variable. The crucial interaction is between the measure of female leadership and the proportion of female workers at the firm. The model predicts a positive coefficient on this interaction.

All our point estimates return an economically significant positive coefficient. A series of 1-tail tests broadly reject a negative interaction in 16 out of 18 specifications. The two specifications not rejecting the null at least at a $10 \%$ level report P-values fairly close to it. ${ }^{44}$ We view these results as fully consistent with Empirical prediction 2 derived from the model.

We conclude our empirical analysis claiming that our theoretical model provides a unified framework able to explain the full set of empirical results found in this section. Our proposed mechanism can account for effects as varied as the differential impact of a CEO's gender along the wage distribution and the strong positive interaction between female leadership and female workers when increasing firms' productivity.

\subsection{Potential efficiency gains from gender quotas}

In order to provide an order of magnitude of the potential efficiency gains generated by increasing the presence of women in corporate leadership positions, for example through gender quotas, we consider a partial-equilibrium exercise using the parameter estimates from our benchmark specification reported in Table 5. We performed two counterfactuals. One is a "targeted" exercise where we allocated a female CEO to all firms whose performance would improve as a result, that is, firms with at least 20 percent of female employees. This results in $51 \%$ of firms with a woman CEO. In the other exercise, we assign a female CEO to the same proportion of firms (51\%) selected randomly. Results are reported in Table 6.

If Female CEOs are allocated randomly, the average percent change is small, and its sign depends on the measure of performance. In contrast, our "targeted" exercise delivers large positive effects in the firms that are assigned a female CEO, and also positive effects overall. For example, in this scenario sales per worker would increase by $14.2 \%$ in the "treated" firms (firms whose CEO's gender has changed) and by $6.7 \%$ in the overall sample of firms. This is because our findings imply large, positive interaction effects between female leadership and the share of female workers.

\footnotetext{
${ }^{44} 14.6 \%$ in specification (c) on TFP and $16.5 \%$ in specification (e) on sales per employee.
} 
Table 6: Impact of gender quotas

\begin{tabular}{lc|ccc|ccc}
\multicolumn{2}{c|}{ Counterfactual } & \multicolumn{3}{c|}{ Average percent gain } & \multicolumn{3}{c}{ Percent gain for treated } \\
CEO Allocation & Quota & Sales & Value added & TFP & Sales & Value added & TFP \\
\hline Female share $>20 \%$ & $51 \%$ & 6.7 & 4.2 & 2.1 & 14.2 & 8.7 & 4.3 \\
Random & $51 \%$ & 1.9 & -2.1 & -2.7 & 3.7 & -4.1 & -5.4
\end{tabular}

Average percent gains relative to fitted data. "Treated" firms are firms that acquire a female CEO.

Although our exercises ignore general equilibrium effects, these results confirm that, based on our estimates, the order of magnitude of the efficiency gains from having a larger female representation in firm leadership can be quite large. ${ }^{45}$

\section{Empirical Results and Alternative Theories of Gender Inequality.}

Our empirical analysis is motivated by a theory of gender inequality focusing on asymmetric information on productivity. We argue in Section 4 that our estimation results are consistent with the predictions of this theoretical framework. At the same time, the theoretical framework provides a unified explanation for the variety of estimation results we obtain. However, other relevant theories of gender inequality can plausibility explain or provide mechanisms for at least some of our empirical results. We will discuss alternative models focusing on two aspects: (i) preferences for workers of a specific gender and (ii) complementarities in technology affecting productivity by gender.

\subsection{Gender Preferences}

The first alternative theory is based on the taste-based discrimination model first proposed by work of Becker (1971). In the standard setup, employers' discrimination is equivalent to assuming in our model that executives receive a disutility from employing workers of the opposite gender. The first implication of this model is that male executives pay women less than equally productive men. The gender wage gap will be larger the larger the disutility from employing women. Female executives will engage in a similar symmetric behavior against men. The result is a gender gap

\footnotetext{
${ }^{45}$ The effect on the average gender wage gap, not shown in the table, is small. In firms acquiring female leadership, the higher wages of female workers at the high end of the distribution are compensated by lower wages at the low end of the wage distribution.
} 
that is homogenous across the wage distribution, which is difficult to reconcile with the differential effects we find along female and males' wage distributions and that we report in Section 4.2.

A theory based on preferences can explain very well the impact of a female CEO at the top of the wage distribution: a positive effect for female workers (which are not discriminated against) and negative for male workers (which are discriminated against). However, it cannot explain the opposite impact observed at the bottom of the distribution where we find that the impact of a female CEO is a wage decrease for female workers and a wage increase for male workers. To be reconciled with all of our evidence, this theory would require the ad-hoc assumption that CEOs preferences differ in intensity by workers' wage or skill level. For example that female CEO have preferences for female workers at the top of the distribution, and hold prejudice against women at the bottom of the distribution.

A preference-based theory is also difficult to reconcile with one of our strongest finding in Section 4.3: the large, statistically significant, and robust effect on firms' performance of the interaction of female leadership with the share of female workers. Discriminating CEOs optimize when workers' marginal products is equal to their marginal cost (wage plus additional psychic cost if the worker is discriminated against). Therefore, employers have no reason to allocate workers to a task where their marginal product is lower, regardless of the worker's gender or the strength of the employer's prejudice. Negative productivity effects are generated when employers misallocate workers across tasks. Hence, the gender composition of the workforce in itself has no implications on productivity without assuming special preferences for task assignment ${ }^{46}$.

\subsection{Complementarities Between Female Leadership and Female Workers.}

The second possible theory focuses on technological complementarities that may affect productivity by gender differently.

The first relevant example of this technology is mentoring. Mentoring is an activity in which upper-level employees are able to increase the productivity of lowerlevel employees with whom they are in contact. ${ }^{47}$ Complementaries by gender takes

\footnotetext{
${ }^{46}$ These implications are robust to the market structure allowing the discriminating firm to survive. As pointed out by Arrow (1973), discriminating firms, being less profitable, cannot survive in a competitive environment, but when non-competitive features of the product market are present discrimination may persist. See for example Black (1995) and Rosén (2003) for theoretical contributions and Flabbi (2010) and Charles and Guryan (2008) for empirical evidence.

${ }^{47} \mathrm{We}$ follow the formal definition provided in Athey et al. (2000). For examples of empirical
} 
place when mentoring is more effective between employees of the same gender. In our case, the upper-level employees are the CEOs and executives and the lowerlevel employees with whom they are in contact may be the entire workforce or just the most skilled or higher ranked workers at the firm, depending on the internal organization of the firm and its size. We do not have enough data variation to study differential impacts for different firm sizes and we do not have enough observables to build different skills levels within the labor force. However, in Section 4.2 we find that female CEOs and executives have a positive impact on wages of women at the top of the distribution. This is consistent with a model of mentoring under the assumptions that CEOs and top executive are more in contact with workers at the top of the wage distribution and that mentoring is more common or effective with employees of the same gender. If mentoring also has a positive impact on improving the matching of mentored workers to tasks, this theory is also consistent with our main results on productivity reported in Section 4.3.

Mentoring, however, has difficulties in explaining our results at the bottom of the wage distributions, namely the fact that female CEOs and executives decrease the wages of women and increase the wages of men in this part of the distribution. Results at the bottom of the wage distribution are more consistent with another technology which has exactly the opposite effect: the so called called "Queen Bee syndrome". ${ }^{48}$ In this theory, women who have managed to reach top-positions in male dominated environment (like the female CEOs and executives that we observe in our data) engage in the opposite of mentoring other women, i.e. they intentionally damage their career prospects. We could not find strong supporting evidence of this technology in the empirical economics literature. Moreover, we find difficult to rationalize a technology where female CEOs act as benevolent mentors for women at the top of the wage distribution and as malevolent "Queen Bees"at the bottom. Finally, it is not clear what the overall impact on productivity should be of such a mixed technology.

A more credible assessment of the mentoring technology in light of our empirical results is that the estimation results consistent with the theory are more robust and precisely estimated than those against it. The crucial discriminating evidence between a mentoring model and our statistical discrimination model is the differential impact of female CEOs and executives at the bottom of the wage distribution but this is also the weakest set of results in our empirical analysis. With our sample

works discussing and assessing empirical implications related to this concept, see Matsa and Miller (2013), Bell (2005), and Bednar and Gicheva (2014)

${ }^{48}$ See Bednar and Gicheva (2014) for use in the economics literature and Staines et al. (1974) for the original concept from psychology. 
size and data variations we could not go beyond the evidence presented in Section 4. Other relevant empirical works available in this area do not provide a definitive answers. If numerous works exist confirming the positive impact of female leadership at the top of the distribution, ${ }^{49}$ only Tate and Yang (2015) find significant impact at the bottom of the wage distribution but with the opposite sign with respect to us. However, they admit that the results may be partially driven by the very few observations of women at the top of the distribution. ${ }^{50}$ We therefore conclude that additional work is needed - possibly using larger data sets with more data variation - in order to check this specific impact of the interaction between workers and firms' leadership.

The second relevant example of gender-specific complementarities in technology is the ability of executives to infer the imperfectly observed productivity of lowerlevel employees. Complementaries by gender appear when this ability is enhanced when executives and employees are of the same gender. This is essentially the assumption we have used in our proposed theoretical framework. In Section 2.3 we have mentioned easier communication between same-gender workers as a possible foundation for the assumption. If this easier communication is enhanced by mentoring activity then the mentoring technology we just discussed may give additional foundation to the main assumption we have used on our theoretical framework.

In conclusion, we believe that our results support the notion that complementarities exist between female skilled workers and firms' female leadership. Our results suggest, but cannot definitively support that the nature of such complementarities takes the form implied by our statistical discrimination model. Additional investigation is therefore needed to confirm the particular form of complementarities taking place at the firm and to identify the relevent mechanisms behind it.

\section{Conclusion}

Motivated by a recent literature showing the importance of executives' personal traits in determining firm policies and outcomes, and by the traditional literature on gender differentials in the labor market, we investigate whether female executives make a difference on gender-specific wage distributions and on firm performance.

\footnotetext{
${ }^{49}$ See for example Matsa and Miller (2013) and Bell (2005).

${ }^{50}$ Bednar and Gicheva (2014) is a recent contribution presenting different but related evidence. They use a panel dataset matching Athletic Directors with Universities and including information about the gender composition in lower levels of the job ladder in order to look at the impact of female leadership on career progression by gender. They do not find evidence that gender is predictive of a supervisor's female-friendliness and therefore do not add conclusive empirical results with respect to our issues.
} 
We find that female leadership increases the variance of women's wages at the firm because of a positive impact on wages at the top of the distribution and a (smaller) negative impact on wages at the bottom. In our preferred specification, female CEOs increase wages for women in the top $25 \%$ of the women's wage distribution by about 10 percentage points and they decrease wages for women in the bottom $25 \%$ by about 3 percentage points. The impact on the men's wage distribution has opposite signs. When looking at the impact on firm performance, we estimate that the interaction between female CEOs and the share of female workers employed at the firm has a positive impact on firm performance. The magnitude of the impact is substantial: in our preferred specification, a female CEO taking over a male-managed firm with at least $20 \%$ women in the workforce increases sales per employee by about $14 \%$.

Our main specification deals with the endogeneity induced by the non-random assignment of executives to firms by estimating firm fixed effects regressions and by introducing controls for both observed and unobserved heterogeneity of the executives and of the non-executive workforce at the firm. We obtain unobserved heterogeneity controls from a first step two-way fixed effects wage regression estimated on a large longitudinal matched employer-employee sample of Italian firms. To address the impact of unobservable time-varying firm characteristics, we also propose an IV strategy based on the assumption that aggregate trends in the proportion of female executives at the regional level are relatively exogenous with respect to the time-varying firm-level heterogeneity we are concerned about.

Our results are robust to the employing our IV strategy and to an additional array of robustness exercises: alternative measures of female leadership, different empirical specifications, different sample selection criteria for firms and workers, and different measures of firm productivity.

Our empirical analysis is motivated by a model of statistical discrimination where female executives are better equipped at interpreting signals of productivity from female workers. As a result of this attenuated information asymmetry, female CEOs taking charge of previously male-led firms are able to reverse statistical discrimination, paying women wages that are closer to their actual productivity and matching them to jobs that are more in line with their skills. Our estimation results are consistent with the prediction of this theoretical framework. At the same time, the theoretical framework provides a unified explanation for the variety of estimation results we obtain. However, we acknowledge that an alternative theory of gender inequality - gender-specific mentoring - can explain most of our empirical results and is in contradiction only with our least robust and least precise estimates. We conclude that additional empirical work is needed to confirm the particular form of 
gender complementarities taking place at the firm.

Interpreting our results through the implications of our theoretical model suggests that there are potentially high costs associated with the under-representation of women at the top of corporate hierarchies. Companies with a substantial female presence would be likely to benefit from assigning women to leadership positions. Results from a partial-equilibrium counterfactual experiment based on our point estimates show that if all the firms with at least $20 \%$ of female workers were lead by female CEOs, they would see their sales per worker increase by about $14.2 \%$. From a public policy point of view, the same partial-equilibrium counterfactual experiment shows that an integrated generalized extension of women in leadership positions would lead to a much smaller ${ }^{51}$ but still positive effect on sales per worker.

\footnotetext{
${ }^{51} 3.7 \%$ instead of $14.2 \%$, see Table 6 . Results on Value Added and TFP would actually turn from positive to negative, with magnitudes always smaller than in the sales per worker case.
} 


\section{A Appendix: Proof of Proposition 1}

Proof. Define $\widehat{s}$ as the signal such that the wage of male and females is the same. From (2.2) note that $\widehat{s}$ is independent of the task assignment, and satisfies $\Phi_{m}(\bar{q} \mid \widehat{s})=$ $\Phi_{f}(\bar{q} \mid \widehat{s}) ; \widehat{s}$ exists and is unique because the cumulatives of two Normal distributions with different variance cross only once. ${ }^{52}$ Under the assumption $\sigma_{\epsilon f}>\sigma_{\epsilon m}, \Phi_{m}$ has thinner tails than $\Phi_{f}$, therefore:

$$
\begin{array}{lll}
1-2 \Phi_{m}(\bar{q} \mid s)<1-2 \Phi_{f}(\bar{q} \mid s) & \text { for all } & s<\widehat{s} \\
1-2 \Phi_{f}(\bar{q} \mid s)<1-2 \Phi_{m}(\bar{q} \mid s) & \text { for all } & s>\widehat{s}
\end{array}
$$

Observe also from (2.2) that either $\widehat{s} \leq \min \left\{\bar{s}_{m}, \bar{s}_{f}\right\}$, or $\widehat{s} \geq \max \left\{\bar{s}_{m}, \bar{s}_{f}\right\}$. To prove it, note that by definition of $\bar{s}_{g}, \Phi_{m}\left(\bar{q} \mid \bar{s}_{m}\right)=\Phi_{f}\left(\bar{q} \mid \bar{s}_{f}\right)=1 / 2$, therefore if $\bar{s}_{m}<\bar{s}_{f}$ we must have $\Phi_{f}(\bar{q} \mid s)<1 / 2<\Phi_{m}(\bar{q} \mid s)$, for all $s \in\left(\bar{s}_{m}, \bar{s}_{f}\right)$; otherwise, if $\bar{s}_{m}>\bar{s}_{f}$ we must have $\Phi_{m}(\bar{q} \mid s)<1 / 2<\Phi_{f}(\bar{q} \mid s)$ for all $s \in\left(\bar{s}_{f}, \bar{s}_{m}\right)$. Hence the crossing of the distributions $\Phi_{m}(\bar{q} \mid \widehat{s})$ and $\Phi(\bar{q} \mid \widehat{s})$ must occur outside of the range $\left(\min \left\{\bar{s}_{m}, \bar{s}_{f}\right\}, \max \left\{\bar{s}_{m}, \bar{s}_{f}\right\}\right)$, that is either (i) $\widehat{s}<\min \left\{\bar{s}_{m}, \bar{s}_{f}\right\}$, or (ii) $\widehat{s}>\max \left\{\bar{s}_{m}, \bar{s}_{f}\right\}$. Case (i) is displayed in Figure 1. ${ }^{53}$ In case (i) both male and female workers with signal $s<\widehat{s}$ are employed in the simple job, and $w\left(s ; \sigma_{\epsilon m}\right)<w\left(s ; \sigma_{\epsilon f}\right)$ holds because of (A.1). But then it must also be the case that $\bar{s}_{m}<\bar{s}_{f}$ because $\Phi_{g}\left(\bar{q} \mid \widehat{s}_{g}\right)<1 / 2$. We need to show that $w\left(s ; \sigma_{\epsilon m}\right)>w\left(s ; \sigma_{\epsilon f}\right)$ for $s>\widehat{s}$. This is immediate from A.2 if males and females are employed in the same job given $s$, that is, for $s: \widehat{s}<s<\bar{s}_{m}$ or $s>\bar{s}_{f}$. For $\bar{s}_{m}<s<\bar{s}_{f}$, we have (by definition of $\bar{s}_{m}, \bar{s}_{f}$ ) male (female) workers employed in the complex (simple) job. From (A.2) $\vee s: \bar{s}_{m}<s<\bar{s}_{f}$, we have $l\left(1-2 \Phi_{f}(\bar{q} \mid s)\right)<h\left(1-2 \Phi_{m}(\bar{q} \mid s)\right)$ hence $w\left(s ; \sigma_{\epsilon m}\right)>w\left(s ; \sigma_{\epsilon f}\right)$ which completes the proof for case(i). Case (ii) is proved symmetrically: male and females with $s \geq \widehat{s}$ are employed in the complex task and receive wages $w\left(s ; \sigma_{\epsilon m}\right)>w\left(s ; \sigma_{\epsilon f}\right)$. Therefore, $\bar{s}_{f}<\bar{s}_{m}$, and wages below $\bar{s}_{m}$ must satisfy $w\left(s ; \sigma_{\epsilon m}\right)<w\left(s ; \sigma_{\epsilon f}\right)$ by an argument similar to that made for case (i).

\footnotetext{
${ }^{52}$ Consider two normal distributions $F, G$ with different variance $\left(\sigma_{F}>\sigma_{G}\right)$. Then, regardless their mean, there exists a unique $\bar{x}: F(x)>G(x)$ for all $x<\bar{x}$, and $F(x)<G(x)$ for all $x>\bar{x}$. To prove this single crossing property, denote with $f, g$ the densities of distributions $F, G$. Because $f, g$ are symmetric around their respective means, and $\sigma_{F}>\sigma_{G}$, the two densities intersect at points $x_{1}, x_{2}$ with $f(x)>g(x)$ if $x<x_{1}$ or $x<x_{2}$, and $f(x)<g(x)$ for $x_{1}<x<x_{2}$. But then $F(x)>G(x)$ for all $x<x_{1}$ and $1-F(x)>1-G(x)$, or $F(x)<G(x)$ for $x>x_{2}$. Hence any intersection between $F$ and $G$ must occur between $x_{1}$ and $x_{2}$, but in this range $f(x)>g(x)$, that is, $F(x)$ has derivative greater than the derivative of $G(x)$, therefore there can be only one intersection.

${ }^{53}$ Case (i) holds whenever $\bar{q}>\mu$, that is whenever employers without signals would place all workers in the simple job, hence a more precise signal implies placing more workers in the complex job.
} 


\section{B Appendix: Additional Results on Benchmark Specification}

We report the estimation results for the benchmark specification. Results for all robustness specifications are available in the online appendix (Flabbi et al. (2016b)).

All the reported standard errors are computed by a bootstrapping procedure. We need to compute standard errors by bootstrapping on specifications (a)-(e) because they include generated regressors (the CEO and worker fixed effects) from the first step. Standard errors in the first stage can be computed only by bootstrap (AKM.) We perform the bootstrapping procedure by resampling at the firm level and by resampling separately firms that never had a female CEO and firms that had a female CEO at least once. This procedure is meant to produce standard errors that are clustered at firm level and stratified by female CEO dummy. Since stratification at the first step may generate samples with zero or very few firms with female

CEOs at the second step, identification of the parameters of interest may not be attained for some bootstrap runs. Therefore, we computed standard errors using only bootstraps with more than 10 firms with a female CEO in the second stage. We run the procedure until we reach 300 valid replications. 


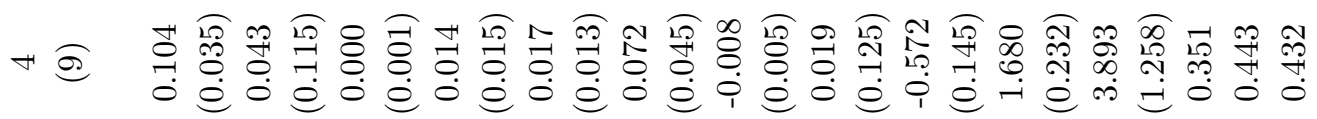

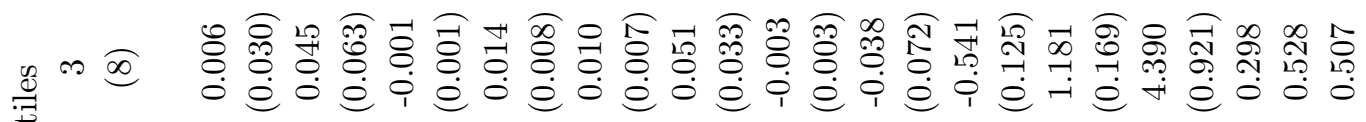
चौ

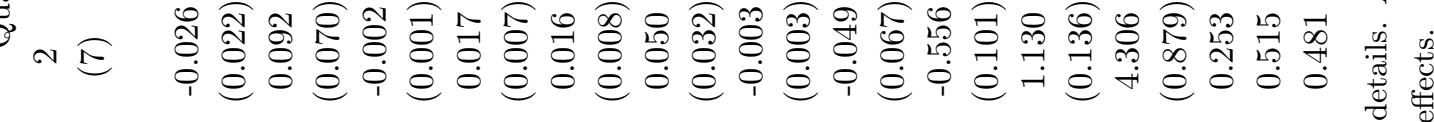

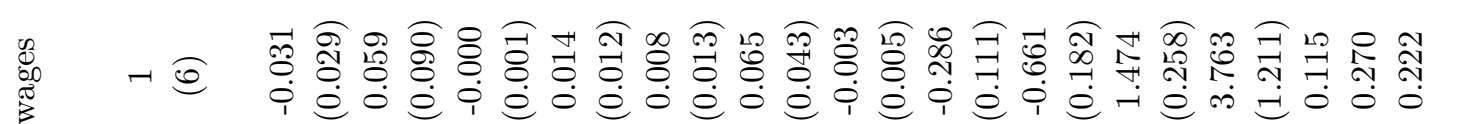

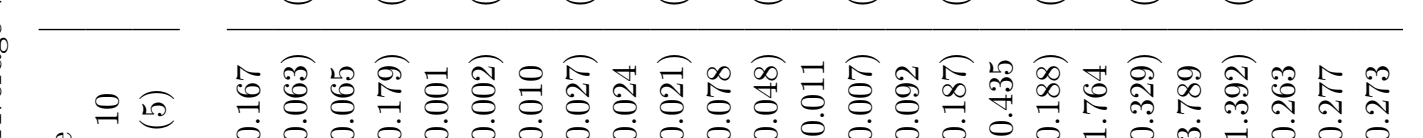

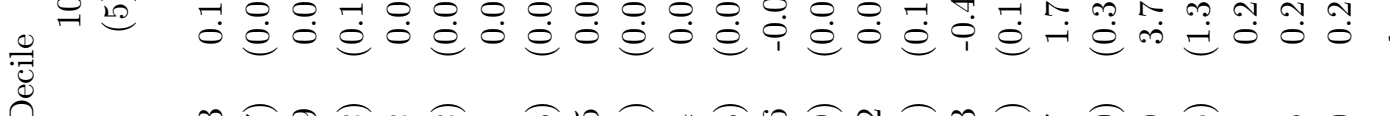

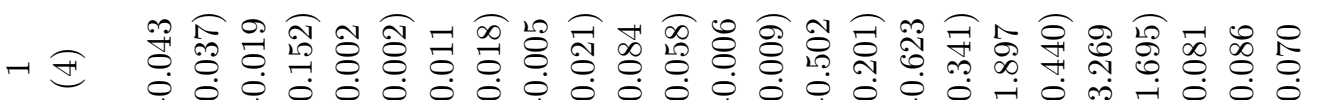

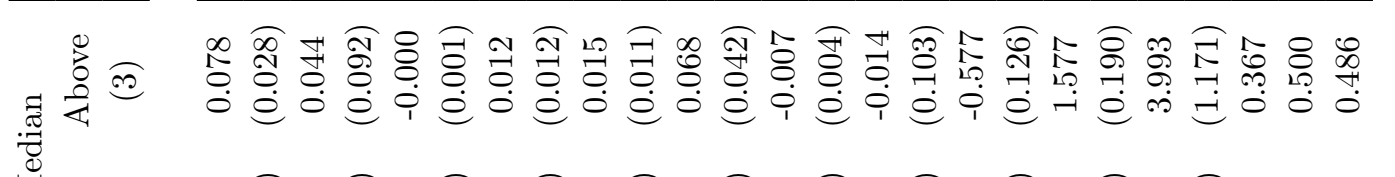
3 (

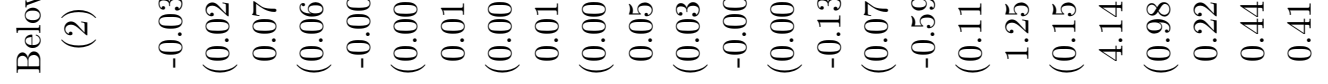




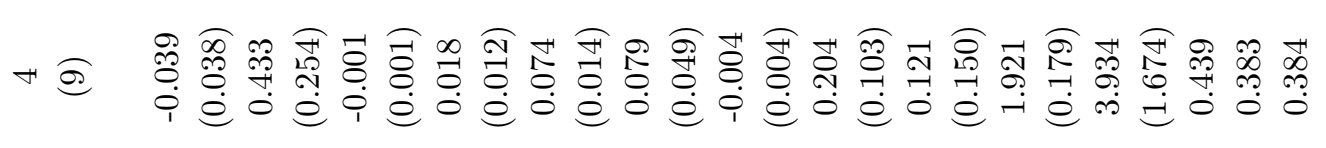

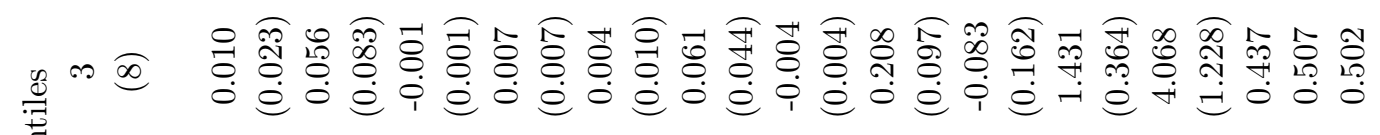
范

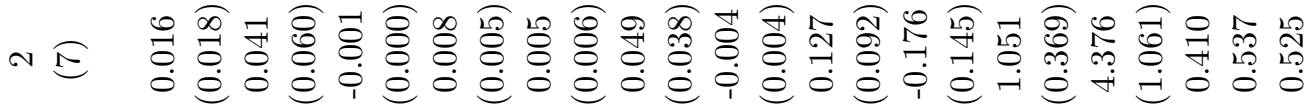

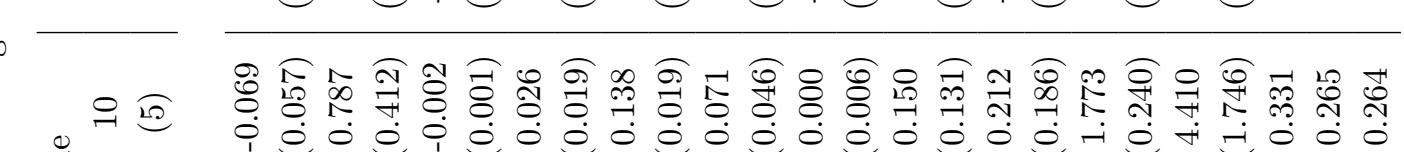

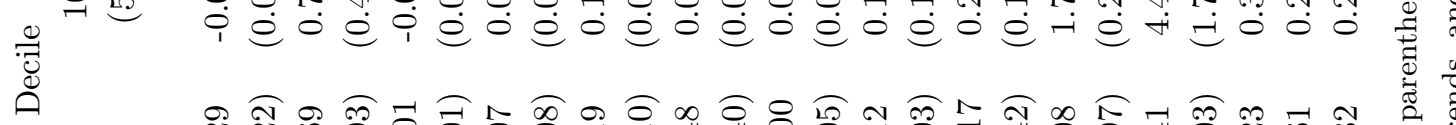

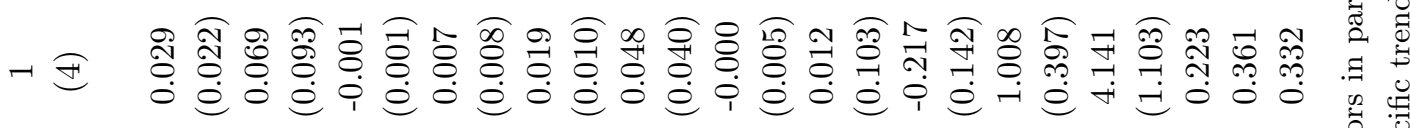

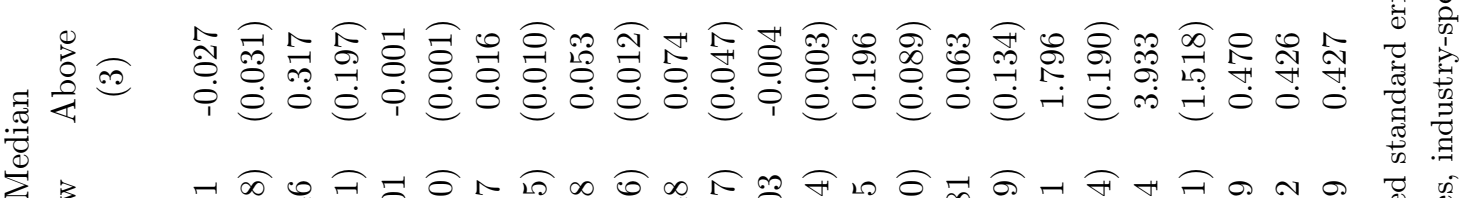

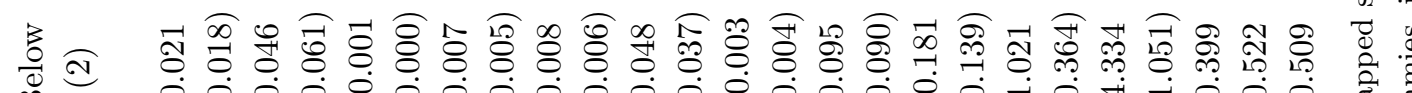
ヘ. 
Table A.3: Estimates on Firm-Level Performance, benchmark specification

\begin{tabular}{|c|c|c|c|c|c|c|}
\hline \multirow{2}{*}{$\begin{array}{c}\text { Dependent } \\
\text { variable } \\
\text { variable } \downarrow\end{array} \rightarrow$} & \multicolumn{2}{|c|}{$\begin{array}{l}\text { Sales per } \\
\text { employee }\end{array}$} & \multicolumn{2}{|c|}{$\begin{array}{l}\text { Value added } \\
\text { per employee }\end{array}$} & \multicolumn{2}{|c|}{ TFP } \\
\hline & (1) & (2) & (3) & (4) & (5) & (6) \\
\hline Female CEO & $\begin{array}{c}0.033 \\
(0.039)\end{array}$ & $\begin{array}{l}-0.120 \\
(0.045)\end{array}$ & $\begin{array}{l}-0.046 \\
(0.038)\end{array}$ & $\begin{array}{l}-0.245 \\
(0.041)\end{array}$ & $\begin{array}{l}-0.059 \\
(0.029)\end{array}$ & $\begin{array}{l}-0.213 \\
(0.039)\end{array}$ \\
\hline Interaction & & $\begin{array}{c}0.610 \\
(0.142)\end{array}$ & & $\begin{array}{c}0.795 \\
(0.169)\end{array}$ & & $\begin{array}{c}0.616 \\
(0.172)\end{array}$ \\
\hline CEO age & $\begin{array}{c}0.212 \\
(0.154)\end{array}$ & $\begin{array}{c}0.209 \\
(0.152)\end{array}$ & $\begin{array}{c}0.442 \\
(0.162)\end{array}$ & $\begin{array}{c}0.438 \\
(0.160)\end{array}$ & $\begin{array}{c}0.320 \\
(0.146)\end{array}$ & $\begin{array}{c}0.316 \\
(0.145)\end{array}$ \\
\hline CEO tenure & $\begin{array}{l}-0.003 \\
(0.001)\end{array}$ & $\begin{array}{l}-0.003 \\
(0.001)\end{array}$ & $\begin{array}{l}-0.002 \\
(0.001)\end{array}$ & $\begin{array}{l}-0.002 \\
(0.001)\end{array}$ & $\begin{array}{l}-0.002 \\
(0.001)\end{array}$ & $\begin{array}{l}-0.001 \\
(0.001)\end{array}$ \\
\hline CEO started $<1980$ & $\begin{array}{c}0.028 \\
(0.014)\end{array}$ & $\begin{array}{c}0.028 \\
(0.014)\end{array}$ & $\begin{array}{c}0.012 \\
(0.015)\end{array}$ & $\begin{array}{c}0.011 \\
(0.015)\end{array}$ & $\begin{array}{c}0.010 \\
(0.015)\end{array}$ & $\begin{array}{c}0.010 \\
(0.015)\end{array}$ \\
\hline CEO fixed eff. & $\begin{array}{c}0.017 \\
(0.019)\end{array}$ & $\begin{array}{c}0.017 \\
(0.018)\end{array}$ & $\begin{array}{c}0.065 \\
(0.017)\end{array}$ & $\begin{array}{c}0.064 \\
(0.017)\end{array}$ & $\begin{array}{c}0.046 \\
(0.017)\end{array}$ & $\begin{array}{c}0.045 \\
(0.017)\end{array}$ \\
\hline Avg. Wkr. age & $\begin{array}{c}0.028 \\
(0.027)\end{array}$ & $\begin{array}{c}0.031 \\
(0.028)\end{array}$ & $\begin{array}{c}0.051 \\
(0.031)\end{array}$ & $\begin{array}{c}0.055 \\
(0.033)\end{array}$ & $\begin{array}{c}0.055 \\
(0.029)\end{array}$ & $\begin{array}{c}0.058 \\
(0.029)\end{array}$ \\
\hline Avg wkr. tenure & $\begin{array}{c}0.005 \\
(0.008)\end{array}$ & $\begin{array}{c}0.004 \\
(0.008)\end{array}$ & $\begin{array}{l}-0.013 \\
(0.007)\end{array}$ & $\begin{array}{l}-0.014 \\
(0.007)\end{array}$ & $\begin{array}{l}-0.030 \\
(0.007)\end{array}$ & $\begin{array}{l}-0.030 \\
(0.007)\end{array}$ \\
\hline$\%$ white collars & $\begin{array}{c}0.269 \\
(0.135)\end{array}$ & $\begin{array}{c}0.254 \\
(0.136)\end{array}$ & $\begin{array}{l}-0.117 \\
(0.154)\end{array}$ & $\begin{array}{l}-0.137 \\
(0.155)\end{array}$ & $\begin{array}{l}-0.082 \\
(0.154)\end{array}$ & $\begin{array}{l}-0.098 \\
(0.154)\end{array}$ \\
\hline Fraction female & $\begin{array}{l}-0.313 \\
(0.234)\end{array}$ & $\begin{array}{l}-0.390 \\
(0.242)\end{array}$ & $\begin{array}{l}-0.496 \\
(0.157)\end{array}$ & $\begin{array}{l}-0.596 \\
(0.158)\end{array}$ & $\begin{array}{l}-0.478 \\
(0.164)\end{array}$ & $\begin{array}{l}-0.556 \\
(0.161)\end{array}$ \\
\hline Avg. wkr. F.E. & $\begin{array}{c}1.217 \\
(0.267)\end{array}$ & $\begin{array}{c}1.284 \\
(0.264)\end{array}$ & $\begin{array}{c}1.636 \\
(0.299)\end{array}$ & $\begin{array}{l}1.724 \\
(0.305)\end{array}$ & $\begin{array}{l}1.438 \\
(0.305)\end{array}$ & $\begin{array}{c}1.506 \\
(0.299)\end{array}$ \\
\hline Constant & $\begin{array}{c}3.089 \\
(0.640)\end{array}$ & $\begin{array}{c}3.020 \\
(0.653)\end{array}$ & $\begin{array}{c}2.072 \\
(0.830)\end{array}$ & $\begin{array}{l}1.983 \\
(0.868)\end{array}$ & $\begin{array}{c}0.422 \\
(0.697)\end{array}$ & $\begin{array}{c}0.353 \\
(0.708)\end{array}$ \\
\hline$R^{2}$ : Between & 0.590 & 0.592 & 0.218 & 0.222 & 0.179 & 0.182 \\
\hline Within & 0.013 & 0.015 & 0.044 & 0.055 & 0.270 & 0.268 \\
\hline Overall & 0.070 & 0.073 & 0.070 & 0.081 & 0.248 & 0.247 \\
\hline
\end{tabular}

Dependent variables are in logs. Boostrapped standard errors in parentheses; see text for details. Additional controls: 15 region dummies, 20 industry dummies, 4 firm-size dummies, year dummies, industry-specific trends, and firm fixed effects. 


\section{Appendix: construction of the instruments and first-year results}

The approach we adopted to construct our instruments is in the style of Bartik (1991) and assumes that there is an exogenous trend in the evolution of female leadership, summarized, for example, by the average fraction of female managers by year and region. This trend should be correlated with the fraction of female managers in each firm in a given year, but not correlated with the time-varying firm-level heterogeneity that may endogenously affect wages and female leadership in a given firm.

We construct two instruments, for both the fraction of female managers employed in firm $j$ at time $t$ (which we denote here with $f_{t, j}$ ) and for the female CEO dummy (denoted with $d_{t, j}$.) We assume that their base year values (1988, the first year of the panel), are exogenous. The endogeneity induced by heterogeneity in the initial conditions is controlled for by the firm fixed effects we include in all of our regressions. Using an older base year would strengthen the exogeneity assumption but induces too many missing values in our sample.

We then compute, for each firm $j$, the average value of the fraction of female executives by year and region over all firms with the exclusion of firm $j$. Denote this average by $\overline{f_{t,-j}^{r(j)}}$, where $r(j)$ is the geographical regional location of firm $j$. We exclude firm $j$ from the average to prevent endogenous factors affecting one firm's female leadership contaminating the average. Next, we compute the growth rates of these averages by year and region relative to the base year. We denote these growth rates as: $\gamma_{t, j}^{r(j)}=\frac{\overline{f_{t,-j}^{r}}}{\overline{f_{1988,-j}^{r}}}$. Our instrument $\tilde{f}_{t, j}$ is constructed multiplying these growth rates by the base-year value of the fraction of female managers:

$$
\tilde{f}_{t, j}=f_{1988, j} \cdot \gamma_{t, j}^{r(j)}
$$

The instrument we use for the female CEO dummy is constructed using a slightly different method. Because the base year value of such variable contains many zeros, using the same approach would generate an instrument without enough variation to capture the realized exogenous growth in female leadership. We therefore first generate a continuous variable by running a probit on the female CEO dummy and computing its predicted value for firm $j$ in year $t$ :

$$
\widehat{d_{j, t}}=\Phi\left(\hat{\beta} Z_{t, j}\right)
$$

where $Z$ includes the age of the CEO, the CEO tenure, the CEO fixed effects, the mean age and tenure of the workforce, the percent of white collar workers, the 
Table A.4: Instrumental variable wage regressions, first stage results

\begin{tabular}{cccc}
\multicolumn{2}{c}{ (a) Female CEO } & (b) Fraction Fem. Managers \\
\hline CEO age & -0.156 & Avg. exec age & -0.003 \\
& $(0.083)$ & & $(0.002)$ \\
CEO tenure & 0.002 & Avg. exec tenure & 0.006 \\
& $(0.001)$ & & $(0.003)$ \\
CEO $<1980$ & -0.000 & & \\
& $(0.014)$ & & \\
Avg. wrk. age & 0.003 & Avg. wrk. age & 0.007 \\
& $(0.004)$ & & $(0.004)$ \\
Avg. wrk. tenure & -0.002 & Avg. wrk. tenure & -0.002 \\
& $(0.004)$ & & $(0.003)$ \\
\% white collar & 0.062 & \% white collar & 0.046 \\
& $(0.061)$ & & $(0.040)$ \\
Fraction female & -0.018 & Fraction female & 0.261 \\
& $(0.090)$ & & $(0.099)$ \\
$\tilde{f}$ & -0.951 & & -0.630 \\
& $(0.206)$ & $\tilde{f}$ & $(0.160)$ \\
$\tilde{d}$ & 0.080 & & 0.092 \\
& $(0.238)$ & & $(0.090)$ \\
\hline R-squared & 0.106 & & 0.228 \\
F-test $(2,233)$ & 10.86 & & 8.63 \\
Prob $>$ F & 0.0000 & & 0.0002
\end{tabular}

Regressors also include the full set of dummies used in the main specification. Standard errors in parenthesis

fraction of females in the workforce, the CEO fixed effect and the mean value of the workers' fixed effects from the two-way fixed effects regression, and three firm-size dummies. The results of this regression are reported in the online appendix. We compute the probit only using data from years 1988 through 1990 and extrapolate the predicted values for the whole sample (ideally we would use only data for the base year, in support to the assumption of exogeneity of the initial value, but we added two more years to add power to the estimates).

Next, we apply to this generated variable, $\widehat{d_{j, t}}$, the same procedure adopted to compute the instrument for the fraction of female managers $f_{j, t}$. Denote this instrument with $\tilde{d}$.

In our IV specifications of the wage equations we instrumented the female leadership variable with both instruments. Table A.4, panel (a) reports the first stage results from the wage equations where the endogenous variable is the Female CEO dummy, whereas panel (b) reports the first stage results from the specifications where 
Table A.5: Instrumental variable performance regressions, first stage results

\begin{tabular}{|c|c|c|c|c|c|}
\hline \multicolumn{2}{|c|}{ (a) Female CEO } & Interaction & (b) Fraction Fem. 1 & Managers & \multirow{2}{*}{$\frac{\text { Interaction }}{-0.001}$} \\
\hline CEO age & -0.141 & -0.020 & Avg. exec age & -0.003 & \\
\hline & $(0.080)$ & $(0.021)$ & & $(0.002)$ & $(0.001)$ \\
\hline CEO tenure & 0.001 & -0.000 & Avg. exec. tenure & 0.006 & 0.001 \\
\hline & $(0.001)$ & $(0.000)$ & & $(0.003)$ & $(0.001)$ \\
\hline $\mathrm{CEO}<1980$ & -0.000 & 0.003 & & & \\
\hline & $(0.014)$ & $(0.004)$ & & & \\
\hline Avg. wrk. age & 0.003 & 0.000 & Avg. wrk. age & 0.007 & -0.002 \\
\hline & $(0.004)$ & $(0.001)$ & & $(0.004)$ & $(0.001)$ \\
\hline Avg. wrk. tenure & -0.002 & 0.000 & Avg. wrk. tenure & -0.002 & -0.001 \\
\hline & $(0.004)$ & $(0.000)$ & & $(0.003)$ & $(0.001)$ \\
\hline$\%$ white collar & 0.066 & 0.015 & $\%$ white collar & 0.046 & 0.014 \\
\hline & $(0.059)$ & $(0.014)$ & & $(0.040)$ & $(0.013)$ \\
\hline Fraction female & -0.038 & 0.048 & Fraction female & 0.260 & 0.161 \\
\hline & $(0.085)$ & $(0.049)$ & & $(0.097)$ & $(0.064)$ \\
\hline$\tilde{f}$ & -0.460 & 0.124 & $\tilde{f}$ & -0.597 & -0.016 \\
\hline & $(0.642)$ & $(0.144)$ & & $(0.536)$ & $(0.079)$ \\
\hline$\tilde{d}$ & 0.074 & -0.033 & $\tilde{d}$ & 0.092 & 0.020 \\
\hline & $(0.233)$ & $(0.033)$ & & $(0.087)$ & $(0.034)$ \\
\hline$\tilde{f} \cdot($ Fraction female $)$ & -0.867 & -1.108 & $\tilde{f} \cdot($ Fraction female $)$ & -0.057 & -0.511 \\
\hline & $(.866)$ & $(0.242)$ & & $(0.678)$ & $(0.093)$ \\
\hline R-squared & 0.111 & 0.301 & & 0.223 & 0.327 \\
\hline F-test $(2,233)$ & 37.74 & 49.77 & & 32.80 & 47.26 \\
\hline Prob $>F$ & 0.0000 & 0.000 & & 0.0000 & 0.000 \\
\hline Cragg-Donald Wald F & & 1.12 & & & 1.02 \\
\hline
\end{tabular}

Regressors also include the full set of dummies used in the main specification. Standard errors in parenthesis

the endogenous variable is the fraction of female managers.

The instrumental variable regressions of the performance regressions contain an additional endogenous variable, the interaction of female leadership with the percent of female workers. For these specification, we include an additional instrument constructed interacting $\tilde{f}$ with the fraction of female workers. Table A.5 contains the first-stage results for the specifications where the Female CEO is the measure of female leadership (panel (a)); and where the fraction of female managers is the measure of female leadership (panel (b)). In each panel, the first column reports the first stage results of the regression where the dependent variable is the measure of female leadership, and the second column reports the results where the dependent variable is the female leadership interacted with the fraction of female workers. 


\section{References}

Abowd, John M., Francis Kramarz, and David N. Margolis, "High wage workers and high wage firms," Econometrica, 1999, 67 (2), 251-333.

_, Robert H. Creecy, and Francis Kramarz, "Computing person and firm effects using linked longitudinal employer-employee data," Center for Economic Studies, US Census Bureau, 2002, 06.

Adams, Renee B. and Daniel Ferreira, "Women in the boardroom and their impact on governance and performance," Journal of Financial Economics, 2009, 94 (2), 291-309.

Ahern, Kenneth R. and Amy K. Dittmar, "The changing of the boards: The impact on firm valuation of mandated female board representation," The Quarterly Journal of Economics, 2012, 127 (1), 137-197.

Albanesi, Stefania and Claudia Olivetti, "Home production, market production and the gender wage gap: Incentives and expectations," Review of Economic dynamics, 2009, 12 (1), 80-107.

_ , _ , and Maria J. Prados, "Gender and Dynamic Agency: Theory and Evidence on the Compensation of Top Executives," Research in Labor Economics, 2015, 42.

Albrecht, James, Anders Björklund, and Susan Vroman, "Is there a glass ceiling in Sweden?," Journal of Labor Economics, 2003, 21 (1), 145-177.

Angier, Michelle and Beth Axelrod, "Realizing the Power of Talented Women," McKinsey Quarterly, 2014, 3 (107-115).

Arrow, Kenneth, "The Theory of Discrimination," in Orley Ashenfelter and Albert Rees, eds., Discrimination in Labor Markets, Princeton, N.J.: Princeton University Press, 1973, pp. 3-33.

Athey, Susan, Christopher Avery, and Peter Zemsky, "Mentoring and diversity," American Economic Review, September 2000, 90 (4), 765-786.

Bagues, Manuel and Maria J. Perez-Villadoniga, "Why Do I Like People Like Me?," Journal of Economic Theory, May 2013, 148 (3), 1292-9.

Bandiera, Oriana, Andrea Prat, Luigi Guiso, and Raffaella Sadun, "Matching firms, managers and incentives," National Bureau of Economic Research Working Paper, 2011, 16691. 
Bartik, Timothy, Who Benefits From State and Local Economic Development Policies?, Kalamazoo, MI: W.E. Upjohn Institute for Employment Research, 1991.

Becker, Gary, The economics of discrimination, Chicago: The University of Chicago Press (first ed. 1957), 1971.

Bednar, Steven and Dora Gicheva, "Are Female Supervisors More FemaleFriendly?," The American Economic Review, 2014, 104 (5), 370-375.

Bell, Linda A., "Women-led firms and the gender gap in top executive jobs," IZA Discussion Papers, 2005.

Bennedsen, Morten, F. Perez-Gonzales, and Daniel Wolfenzon, "Evaluating the Impact of The Boss: Evidence from CEO Hospitalization Events," Unpublished Manuscript, 2012.

Bertrand, Marianne and Antoinette Schoar, "Managing with Style: the Effect of Managers on Firm Policies," The Quarterly Journal of Economics, 2003, 118 (4), 1169-1208.

- and Kevin F. Hallock, "The Gender gap in top corporate jobs," Industrial and Labor Relations Review, October 2001, 55 (1), 3-21.

_ , Sandra Black, Sissel Jensen, and Adriana Lleras-Muney, "Breaking the Glass Ceiling? The Effect of Board Quotas on Female Labor Market Outcomes in Norway," Unpublished Manuscript, 2014.

Black, Dan, "Discrimination in an Equilibrium Search Model," Journal of Labor Economics, 1995, 13 (2), 309-334.

Blau, Francine D and Lawrence M Kahn, "The US gender pay gap in the 1990s: Slowing convergence," NBER Working Papers, 2004.

Bloom, Nicholas and John Van Reenen, "Measuring and explaining management practices across firms and countries," The Quarterly Journal of Economics, 2007, 122 (4), 1351-1408.

_ and _ , "Why do management practices differ across firms and countries?," The Journal of Economic Perspectives, 2010, 24 (1), 203-224.

Card, David, Jörg Heining, and Patrick Kline, "Workplace Heterogeneity and the Rise of West German Wage Inequality," The Quarterly Journal of Economics, August 2013, 128, 967-1015. 
Cardoso, Ana Rute and Rudolf Winter-Ebmer, "Female-Led Firms and Gender Wage Policies," Industrial and Labor Relations Review, 2010, 61 (1), 143-63.

Charles, Kerwin Kofi and Jonathan Guryan, "Prejudice and Wages: An Empirical Assessment of Becker's The Economics of Discrimination," Journal of Political Economy, 2008, 116 (5), 773-809.

Cooper-Patrick, Lisa, Joseph J. Gallo, Junius J. Gonzales, Hong Thi Vu, Neil R. Powe, Christine Nelson, and Daniel E Ford, "Race, gender, and partnership in the patient-physician relationship," JAMA, 1999, 282 (6), 583-589.

Cornell, Bradford and Ivo Welch, "Culture, information, and screening discrimination," Journal of Political Economy, 1996, pp. 542-571.

Dezsö, Cristian L. and David Gaddis Ross, "Does female representation in top management improve firm performance? A panel data investigation," Strategic Management Journal, 2012, 33 (9), 1072-1089.

Dindia, Kathryn and Daniel J. Canary, Sex differences and similarities in communication, Psychology Press, 2006.

Eaton, Morris L., Multivariate Statistics : A Vector Space Approach Wiley series in probability and mathematical statistics, New York : Wiley, 1983.

Eckstein, Zvi and Eva Nagypal, "The evolution of US earnings inequality: 19612002," Federal Reserve Bank of Minneapolis Quarterly Review, 2004, 28 (2), 10-29.

Ellison, Sara Fisher and Wallace P. Mullin, "Diversity, Social Goods Provision, and Performance in the Firm," Journal of Economics 85 Management Strategy, 2014, 23 (2), 465-481.

Fadlon, Yariv, "Statistical Discrimination and the Implication of EmployerEmployee Racial Matches," Journal of Labor Research, 2015, 36 (2), 232-248.

Fang, Hanming and Andrea Moro, "Theories of Statistical Discrimination and Affirmative Action: A Survey," in Jess Benhabib, Matthew O. Jackson, and Alberto Bisin, eds., Handbook of Social Economics, Vol. 1A, The Netherlands: North Holland, 2011, chapter V, pp. 133-200.

Farrell, Kathleen A and Philip L Hersch, "Additions to corporate boards: the effect of gender," Journal of Corporate Finance, 2005, 11 (1), 85-106. 
Flabbi, Luca, "Prejudice and gender differentials in the US labor market in the last twenty years," Journal of Econometrics, 2010, 156 (1), 190-200.

_ , Claudia Piras, and Scott Abrahams, "Female Corporate Leadership in Latin America and the Caribbean Region: Representation and Firm-level Outcomes," IDB Working Paper, 2016, 655.

_ , Mario Macis, Andrea Moro, and Fabiano Schivardi, "Do Female Executives Make a Difference? The Impact of Female Leadership on Gender Gaps and Firm Performance. External Appendix," Unpublished Manuscript, 2016. (download link).

Gabaix, Xavier and Augustin Landier, "Why has CEO pay increased so much?," The Quarterly Journal of Economics, 2008, 123 (1), 49-100.

Gagliarducci, Stefano and M. Daniele Paserman, "Gender Interactions in Firm Hierarchies: Evidence from Linked Employer-Employee Data," Research in Labor Economics, 2015, 41, 343-375.

Gayle, George-Levi, Limor Golan, and Robert A. Miller, "Gender Differences in Executive Compensation and Job Mobility," Journal of Labor Economics, 2012, $30(4), 829-872$.

Iranzo, Susana, Fabiano Schivardi, and Elisa Tosetti, "Skill Dispersion and Firm Productivity: An Analysis with Employer-Employee Matched Data," Journal of Labor Economics, 2008, 26 (2), 247-285.

Kaplan, Steven N., Mark M. Klebanov, and Morten Sorensen, "Which CEO characteristics and abilities matter?," The Journal of Finance, 2012, 67 (3), 973-1007.

Lang, Kevin, "A language theory of discrimination," The Quarterly Journal of Economics, 1986, pp. 363-382.

Lazear, Edward P., Kathryn L. Shaw, and Christopher T. Stanton, "The Value of Bosses," National Bureau of Economic Research Working Paper, 2012, $1831 \%$.

Lippi, Francesco and Fabiano Schivardi, "Corporate control and executive selection," Quantitative Economics, 2014, 5 (2), 417-456. 
Lucifora, Claudio and Daria Vigani, "What If Your Boss Is a Woman? Work Organization, Work-Life Balance and Gender Discrimination at the Workplace," IZA Discussion Papers, 2016, $973 \%$.

Malmendier, Ulrike and Geoffrey Tate, "CEO overconfidence and corporate investment," The Journal of Finance, 2005, 60 (6), 2661-2700.

Mast, Marianne Schmid, Judith A. Hall, and Debra L. Roter, "Disentangling physician sex and physician communication style: their effects on patient satisfaction in a virtual medical visit," Patient education and counseling, 2007, 68 (1), 16-22.

Matsa, David A. and Amalia R. Miller, "A Female Style in Corporate Leadership? Evidence from Quotas," American Economic Journal: Applied Economics, 2013, 5 (3), 136-69.

Morgan, John and Felix Várdy, "Diversity in the Workplace," The American Economic Review, 2009, pp. 472-485.

Olley, G. Steven and Ariel Pakes, "The Dynamics of Productivity in the Telecommunications Equipment Industry," Econometrica, 1996, 64, 1263-1297.

Phelps, Edmund S, "The Statistical Theory of Racism and Sexism," The American Economic Review, 1972, 62 (4), 659-661.

Rathore, Saif S., Jersey Chen, Yongfei Wang, Martha J. Radford, Viola Vaccarino, and Harlan M. Krumholz, "Sex differences in cardiac catheterization: the role of physician gender," Jama, 2001, 286 (22), 2849-2856.

Rose, Caspar, "Does female board representation influence firm performance? The Danish evidence," Corporate Governance: An International Review, 2007, 15 (2), 404-413.

Rosén, Åsa, "Search, Bargaining, and Employer Discrimination," Journal of Labor Economics, 2003, 21 (4), 807-829.

Scollon, Ron, Suzanne Wong Scollon, and Rodney H. Jones, Intercultural communication: A discourse approach, John Wiley \& Sons, 2011.

Smith, Nina, Valdemar Smith, and Mette Verner, "Do women in top management affect firm performance? A panel study of 2,500 Danish firms," International Journal of Productivity and Performance Management, 2006, 55 (7), 569-593. 
Staines, Graham, Carol Tavris, and Toby Jayaratne, "The Queen Bee Syndrome," Psychology Today, 1974, 7 (8), 63-66.

Tate, Geoffrey and Liu Yang, "Female Leadership and Gender Equity: Evidence from Plant Closure," Journal of Financial Economics, 2015, 117 (1), 77-97.

Tervio, Marko, "The difference that CEOs make: An assignment model approach," The American Economic Review, 2008, 98 (3), 642-668.

Wolfers, Justin, "Diagnosing discrimination: Stock returns and CEO gender," Journal of the European Economic Association, 2006, 4 (2-3), 531-541. 